\title{
LIBRAE, STATERAE Y AEQUIPONDIA DE SEGOBRIGA. INSTRUMENTOS DE PESAR HALLADOS EN LA CIUDAD Y SU ENTORNO
}

\author{
LIBRAE, STATERAE AND AEQUIPONDIA IN SEGOBRIGA. WEIGHING INSTRUMENTS DISCOVERED IN \\ THE CITY AND ITS SURROUNDINGS
}

Recepción: 29-05-2017

Aceptación: 07-07-2017

\section{Resumen}

Se analiza en este artículo un conjunto de 25 piezas vinculadas a instrumentos de pesar procedentes de la ciudad de Segobriga y su entorno. Se trata principalmente de contrapesos de staterae, uno de ellos con indicación epigráfica de su peso en libras, y varias librae de pequeño tamaño. El contexto arqueológico de los hallazgos ofrece una cronología que abarca desde el primer tercio del siglo I a.C. hasta el III d.C.

Palabras clave. Librae; staterae; aequipondia; Segobriga.

\author{
ROSARIO CEBRIÁN FERNÁNDEZ \\ Universidad Complutense de Madrid \\ marcebri@ucm.es \\ http://orcid.org/0000-0002-5560-1191 \\ IGNACIO HORTELANO UCEDA \\ Equipo Técnico de Segobriga \\ ignacio.hortelano@gmail.com \\ http://orcid.org/0000-0002-3883-2510
}

\begin{abstract}
This article considers a collection of 25 items related to weighing instruments from the Roman city of Segobriga and its surroundings. These are mainly staterae counterweights, one of them showing its weight in pounds, and several small librae. Their archaeological context provides a chronology that spans from the 1st century $\mathrm{BC}$ to the end of the 3rd century AD.
\end{abstract}

Key words. Librae; staterae; aequipondia; Segobriga. 
El material metálico correspondiente a instrumentos de pesar que damos a conocer en este artículo es fruto de los trabajos arqueológicos en Segobriga en el período 1982-2009, al que se unen varias piezas localizadas con detector de metales en el entorno de la ciudad y una pesa de libra vinculada casi con toda probabilidad al cerro de Alvarfáñez (Huete), identificado con la ciudad de Opta.

El contexto arqueológico de hallazgo de librae, staterae y aequipondia permite establecer la cronología de algunas de ellas. Es el caso de los contrapesos localizados en el entorno de la ciudad, que pueden vincularse a librae de precisión para el pesado de los proyectiles de honda hallados en el paraje de Los Enebrales, cuyo peso medio se sitúa circa $49 \mathrm{~g}$ y se adscriben tipológicamente al período de las guerras sertorianas (Cebrián, 2014: 173-188). Mientras las excavaciones en el foro de la ciudad han evidenciado el uso de librae y contrapesos de staterae de plomo con un anillo de suspensión fabricado en hierro, en un taller artesano instalado en una de las tabernae situadas en el costado meridional del espacio público segobrigense durante el siglo III d. C. (Fig. 1).

\section{LIBRAE Y STATERAE: LOS INSTRUMENTOS DE PESAR EN ÉPOCA ROMANA}

Las balanzas son instrumentos de medida nacidos de la necesidad del ser humano de cuantificar mercancías que por otros medios son difíciles de computar, como las materias primas -metales, piedras preciosas-, los productos agrícolas a granel -cereales, fibras textilesu otros géneros poco mensurables como la lana. $\mathrm{Su}$ origen se vincula a los primeros trueques comerciales en los que se hizo preciso determinar las cantidades exactas de los bienes objeto de intercambio, estableciéndose una íntima relación entre su invención y los procesos iniciales de mercantilización (Pare, 2013: 508, 522-524). A diferencia del resto de sistemas de medición los módulos empleados en el cálculo del peso no resultan de dimensiones anatómicas, como las medidas de longitud, o de la capacidad de objetos comunes de la vida diaria, como las de volumen, sino que expresan conceptos cuantitativos específicos que no se conciben al margen del desarrollo de la balanza (Damerow, Renn, Rieger y Weinig, 2000: 2).

Las balanzas más antiguas conocidas corresponden al tipo de dos platillos con brazos de la misma longitud. Su invención se sitúa en la primera mitad del tercer mileno a.C. con base en representaciones pintadas del Imperio Antiguo egipcio en las que aparecen escenas relativas al peso de metales preciosos, a transacciones comerciales de la vida cotidiana y, principalmente, a la denominada psicostasis o pesaje de los muertos en el juicio de Osiris (Pasquale, 2004: 284-287). En ellas, el cálculo de la masa de un determinado objeto se realiza mediante su comparación con otro de masa estándar que se toma por unidad.
Consiste básicamente en una palanca de primer género apoyada sobre su punto medio que se dota de sendos platillos colgados de sus extremos. En uno de ellos se dispone el objeto cuyo peso se pretende averiguar mientras que en el opuesto se colocan tantas piezas de peso conocido como sea necesario hasta restablecer la horizontalidad de la varilla y, por consiguiente, el equilibrio de las masas a ambos lados de la balanza, compensando de esta forma los momentos antagonistas de ambos.

La balanza de brazos asimétricos, en cambio, se considera de época helenística y se define como una innovación tecnológica derivada de la aplicación del principio de palanca que formuló, entre otros, Arquímedes de Siracusa. Al igual que en la balanza de brazos iguales, el método empleado para el pesaje del objeto reside en la compensación de los momentos contrarios de su masa y de la de un contrapeso de referencia, pero se distingue de aquella en que, gracias al alargamiento del brazo de potencia, el efecto se consigue con la aplicación de una fuerza considerablemente menor. Conociendo la igualdad axiomática que se da en una palanca entre el producto de la potencia por su brazo y el de la resistencia por el suyo, es posible el establecimiento de una graduación del brazo largo que proporciona la lectura de la medición dependiendo de la posición del contrapeso cursor al producirse la nivelación del aparato.

En el mundo romano coexistieron ambos tipos de balanza. La de brazos iguales constaba de un brazo horizontal o cruz llamado scapus y de dos platillos denominados lances, de donde proceden el término castellano balanza y sus correspondientes en lenguas romances a través de la voz del latín vulgar *bilancia y este a su vez del latín tardío bilanx, -ancis. El aparato se hacía pender de un punto central o fulcrum donde un dispositivo vertical, llamado examen o lingula, servía de fiel. Recibió indiferentemente las denominaciones libra, talentum y trutina, aunque para Isidoro de Sevilla (Etym. XVI, 25, 4) esta última designación se reservaba exclusivamente para los ejemplares de mayor tamaño destinados al pesaje de grandes cargas.

Debido a sus grandes dimensiones se considera que estas enormes trutinae pudieron permanecer colgadas de manera permanente de una viga o bien disponer de un soporte fijo de madera en forma de columnilla o de caballete. Fueron construidas en su mayor parte con materiales perecederos, siendo de madera sus brazos, soporte y platos, y de cuerda los dispositivos de suspensión de estos últimos. Tan solo algunos elementos debieron estar realizados en bronce, especialmente el fiel y los extremos del travesero donde se situaban los enganches para colgar las plataformas de pesaje (Tarpini, 2001: 180-181). Las grandes pesas empleadas en estas balanzas estaban habitualmente hechas de piedra con su peso indicado en forma de numeral en una de sus caras. Solían disponer de asas de bronce para facilitar su manejo. 


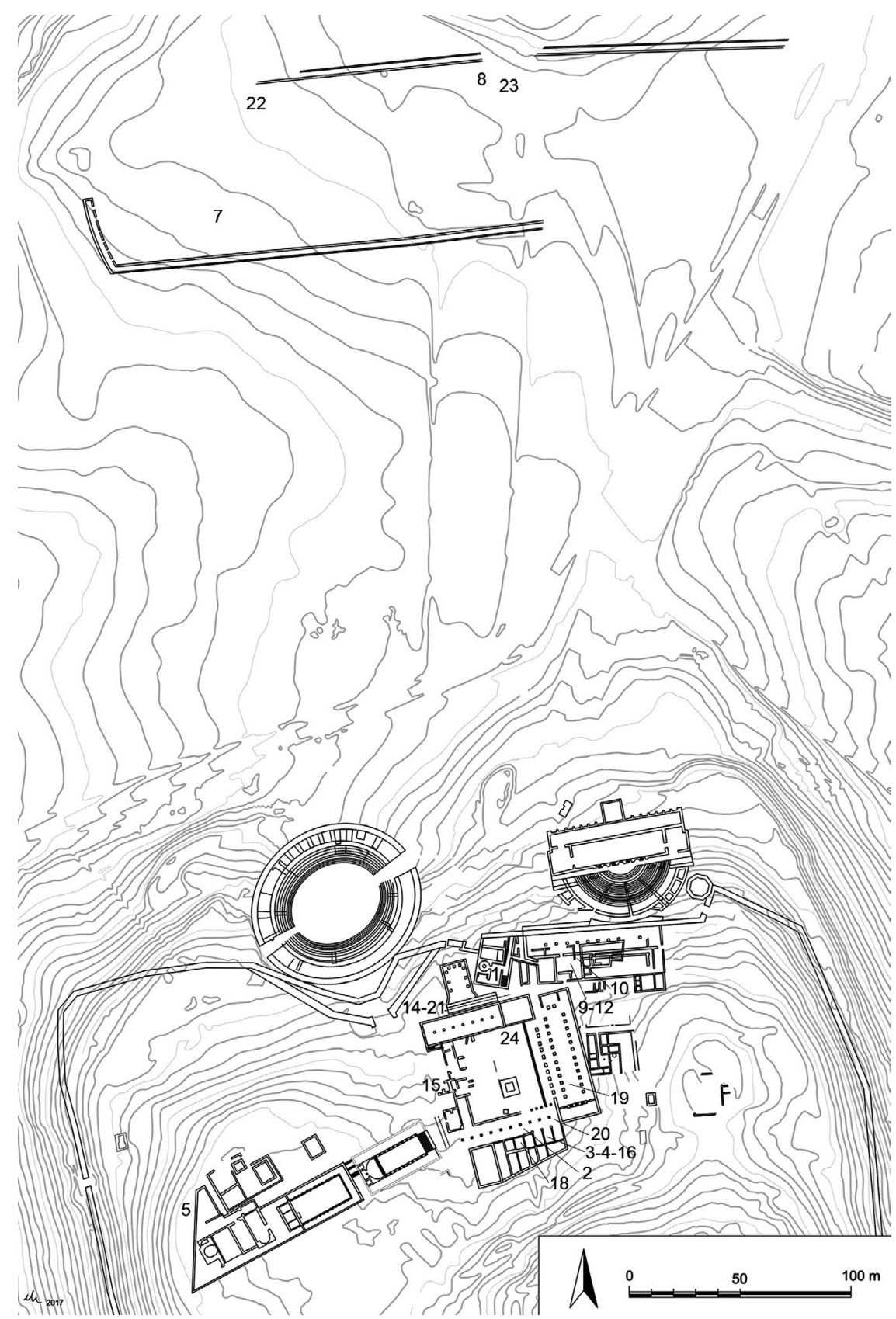

Figura 1: Situación de los hallazgos de instrumentos de pesar en la ciudad de Segobriga. El número de la pieza corresponde al del catálogo.

Los ejemplares de menor tamaño se construyeron principalmente en bronce. Por lo general, consistían en una simple varilla de sección circular dotada en su eje de un dispositivo de suspensión. A ambos extremos, que frecuentemente presentaban una decoración anillada, se disponían sendos aros -ansae- de donde se colgaban los platillos mediante juegos de tres o cuatro cadenillas o alambres de bronce. Según las propiedades físicas de las mercancías estos platillos podían ser más o menos profundos e incluso planos si se destinaban a géneros sólidos. Para facilitar su transporte, algunas de estas balanzas disponían de brazos plegables compuestos por un pequeño segmento central fijo que se remataba en sus extremos con prolongaciones unidas a él por medio de bisagras similares a las empleadas en las regulae (Pasquale, 2004: 292, nota 33). En posición de plegado, los brazos se replegaban hacia la parte superior de la balanza protegiendo el dispositivo de suspensión y el fiel.

Se conocen ejemplares de balanzas de brazos iguales de tamaño muy reducido para los que se utilizó, según Isidoro de Sevilla (Etym. XVI, 25, 4), la denominación momentana o moneta debido a que se emplearon para verificar el peso de las monedas, algo imprescindible en un sistema monetario caracterizado por la pluralidad de emisiones de diferentes valores nominales y ponderales (Tarpini, 2001: 182). Con el fin de incrementar la precisión de las pesadas se dotaron de indicadores que determinaban la inclinación del travesero con respecto al elemento de 
suspensión vertical. Algunas de ellas solo dispusieron de un único platillo en contraposición a una pesa fija, el monopondium, en ocasiones una simple moneda, que se situaba en el brazo contrario constituyendo el peso preestablecido para el contraste. Para M. della Corte (1912: 37-40, fig. 9) y G. di Pasquale (1998: 663-666, fig. 2) este tipo de instrumento supuso el precedente de las staterae o balanzas de brazos desiguales, por medio de trasformar este contrapeso fijo en un elemento móvil (aequipondium) y desplazar el punto de suspensión hacia el extremo del brazo de carga.

Las staterae recibieron genéricamente la denominación campana en referencia a su origen geográfico (Daremberg y Saglio, 1900: 1225). Su mecanismo se distingue del de las librae por la posición absolutamente descentrada que ocupa el dispositivo del que se suspende el instrumento, de la que resulta un travesero dividido en dos brazos de medidas asimétricamente diferentes. Dependiendo de la manera en que se consiga la nivelación del aparato pueden distinguirse balanzas de fulcro variable, denominadas en la bibliografía anglosajona «Bismartype», «staderasvedese» o «danese» en la italiana y «Besmar-Waage» en la germánica, balanzas de contrapeso variable, las normalmente conocidas en castellano como romanas, «steelyards» en inglés o «Schnellwaagen» en alemán, y aquellas otras en las que lo que varía de posición es el objeto pesado, inexistentes en época clásica y que carecen de una denominación específica.

Las balanzas del tipo Bismar no fueron excesivamente difundidas en el mundo romano. Los ejemplares más frecuentes de este tipo estaban formados por una barra rígida horizontal, de sección circular, rematada en uno de sus extremos por un aro del que se colgaba la carga y en el opuesto por un contrapeso fijo, en ocasiones una representación animal figurada a modo de prótomo. Disponían de un mecanismo de suspensión móvil en forma de argolla rectangular que podía desplazarse a lo largo de una plancha graduada de bronce dispuesta verticalmente sobre el brazo a modo de puente. Al ser la posición de su fulcro variable, esta escala presentaba divisiones cuya separación aumentaba de forma inversamente proporcional a su distancia al contrapeso, resultando imprecisas y de alcance bastante limitado. También se conoce un ejemplar pompeyano de este tipo de balanzas para cuya construcción, sin duda improvisada, se utilizó un cazo de bronce al que se le fijó un aequipondium reaprovechado de una statera anterior y se le dotó de un elemento móvil de suspensión a través de una ranura graduada practicada en su mango (Mutz, 1983: 1213, Abb. 4; Damerow, Renn, Rieger y Weinig, 2000: 12-17).

Las balanzas de fulcro fijo y contrapeso variable fueron las más frecuentes en época clásica. Estaban constituidas por una larga barra rectilínea -scapusdotada de uno o varios dispositivos de suspensión -fulcrum-, que ocupaban una posición desplazada con respecto a su centro de gravedad, lo que determina su división en dos brazos de longitudes muy desiguales. Frecuentemente estuvieron construidas en bronce $\mathrm{o}$ hierro pero también se conocen ejemplares de mayor tamaño que debieron estar fabricados en madera y que se reforzaron mediante elementos metálicos en sus sujeciones y remates (Corte, 1912). El producto se suspendía muy próximo al fiel mediante ganchos o sobre un platillo -lanx - colgado de cadenillas del brazo más corto o brazo de carga, que solía ser de sección rectangular aplanada dispuesta en vertical. El brazo opuesto presentaba por lo general sección cuadrada, rectangular, romboidal u ovoide, orientada con una de sus aristas hacia el extremo superior con el fin de que pudiera ser graduada y servir de escala para un cursor metálico del que pendía el contrapeso móvil o aequipondium. Esta escala presentaba comúnmente signos numéricos incisos que indicaban los valores ponderales correspondientes a las unidades de referencia, ya fueran libras o cualquiera de sus submúltiplos (Tarpini, 2001: 185).

La disposición de más de un dispositivo de suspensión permitió ampliar el rango de pesada del instrumento por lo que proliferaron las staterae dotadas de dos, tres y, menos habitualmente, cuatro fulcros. Cada uno de ellos se situaba sobre una de las caras del brazo de carga a distinta distancia del punto de suspensión de la mercancía, correspondiéndoles una escala específica en el brazo graduado. El correcto diseño del aparato consintió cubrir, sin interrupciones ni pérdida de precisión, desde la pesada menor, con la carga situada en la posición más alejada del fulcro y el contrapeso más próximo a él, hasta la mayor, con la disposición inversa.

El principio de palanca aplicado en las staterae se aprovechó en algunos modelos de librae para aquilatar pesadas de precisión. Para ello se dotó al brazo de carga de una escala graduada en su cara superior y de un pequeño aequipondium con cursor que facilitaba la consecución del equilibrio del aparato sin necesidad de usar las pesas de menor tamaño (Pasquale, 2004: 322).

Las staterae de contrapeso móvil fueron las balanzas más corrientes en las operaciones comerciales minoristas en la vida cotidiana romana debido a su versatilidad, portabilidad y facilidad de manejo. Pese a que las librae eran, por la simplicidad y trasparencia de su mecanismo, más exactas y precisas, su principal inconveniente resultó de la necesidad de contar con múltiples pesas que permitieran abarcar un amplio rango de pesadas. El valor de cada una de ellas, además, debía ser contrastado por una autoridad oficial en evitación de fraudes, siendo frecuente que tanto el vendedor como el comprador dispusieran de pesos propios para verificar la equidad de las transacciones (Corti, 2001b: 334). Las staterae, sin embargo, contaban con escalas que se graduaban en los talleres de producción garantizando de esta forma su fidelidad (Corti, 2001a: 191-192). 


\section{PONDERA Y AEQUIPONDIA: PESAS DE BA- LANZA Y CONTRAPESOS DE ROMANA}

La primera distinción que cabe establecer es de carácter funcional, reservando el término pesa -ponduspara las piezas carentes de elemento de suspensión que se usaron en las librae y la denominación contrapeso -aequipondius- para los mecanismos móviles con cursor empleados en las staterae. Las pesas son por lo tanto independientes de la báscula en sí, resultando eficaces en cualquier instrumento de brazos simétricos capaz de soportar su peso, mientras los contrapesos solo trabajan en el instrumento para el que han sido diseñados y al cual pertenecen.

La bibliografía existente sobre el tema es extensa aunque por lo general excesivamente parcial al centrarse de manera casi exclusiva en las piezas con títulos inscritos o de mayor calidad estética. Las inscripciones sobre pesas y staterae han sido objeto desde siempre de la investigación epigráfica dentro de la categoría de instrumenta y los pequeños pondera con indicación de su valor han engrosado asimismo desde antiguo los gabinetes numismáticos, proporcionando series calibradas precisas con las que abordar el análisis de los pesos y medidas en época clásica. Del mismo modo los aequipondia figurados y las grandes pesas lapídeas y de bronce con asas ricamente decoradas han suscitado el interés de anticuarios e historiadores del arte, siendo objetos tradicionales de coleccionismo, que suelen conservarse desprovistos de las balanzas a las que pertenecieron y sin referencias a su lugar de origen o contexto de hallazgo (Corti, 2001a: 196).

El carácter artístico de estas piezas contrasta con la habitual austeridad ornamental presente en la mayor parte de los instrumentos de pesada, especialmente en balanzas de brazos iguales y en las pesas y contrapesos de los aparatos de uso más común. Muchos de los ejemplares hoy día conocidos de este tipo de elementos proceden de recogidas superficiales, de hallazgos casuales o, más frecuentemente, de rebuscas clandestinas, acrecentando aún más la descontextualización del material. Por otra parte, las balanzas, como tales instrumentos de precisión, debieron ser objetos muy cuidados por parte de sus propietarios y, aunque se han descrito las principales variantes tipológicas que definen la evolución formal de las staterae a lo largo de la antigüedad clásica (Franken, 1993), la simplicidad de sus mecanismos y componentes debió propiciar su perduración, siendo frecuente su hallazgo en niveles tardíos.

El número de staterae conocido en España es limitado, con ejemplares en el Collet de Sant Antoni en Calonge (Palol, 1950), Vélez Blanco (Sentandreu, 1959; Albiach y Pérez Mínguez, 2009), Pollentia (Arribas, Tarradell y Woods, 1978: $36 \mathrm{n}^{\circ}$ 3, fig. 18,3), Baena (Chaves Tristán, 1982), Calahorra (Hernández Prieto, 1984: 161-163), Sevilla (Fernández Gómez, 1991) y València (Aranegui, 1989; 1991).
Más numerosos son los aequipondia publicados, con una primera aproximación a raíz de la exposición sobre los Bronces Romanos en España (Caballero, 1990: 342-344) y una posterior puesta al día por S. F. Pozo (1994). Recientemente se ha publicado la pieza de Sofuentes (Erice Lacabe, 2014) y se ha revisado desde el punto de vista funcional e iconográfico la ya conocida del puerto de Tarraco (Rodríguez Martorell y Ruiz de Arbulo, 2016).

El resto de materiales de pesaje hay que rastrearlos en la publicación de memorias de excavación y en los repertorios de pequeños hallazgos, siendo inexistentes las monografías al respecto. Una primera sistematización de balanzas y ponderales conocidos en Hispania fue realizado por F. Chaves y R. Pliego (2007: 237-250).

C. Corti, P. Pallante y R. Tarpini (2001: 298) establecen en su estudio sobre los instrumentos de pesaje de la provincia de Módena una distinción no solo funcional sino también tipológica entre pesas y contrapesos, manifestando lo complejo de definir el ámbito concreto de uso de algunas piezas, que pudieron haber servido también de plomos de pesca, pesas de telar o plomadas. Reconocen dos sistemas de enganche derivados de la técnica empleada en su fabricación, con ejemplares que presentan un anillo de suspensión fundido simultáneamente al resto del cuerpo y otros que poseen una argolla de hierro inserta en la masa de plomo. Aparte de los ejemplares de mayor calidad que se decoraron con representaciones figuradas, describen contrapesos en forma de anforisco, de bellota, de cesta o de bastoncillo así como otros más simples de desarrollo globular, lenticular, cilíndrico o troncocónico.

Por su parte, R. Tyrrell (2015), al clasificar los pesos de plomo procedentes del asentamiento britanorromano de Heybridge, distingue tres grandes tipos según el método de suspensión: los ejemplares del Tipo A presentan sus cuerpos perforados y morfológicamente se definen piezas en forma de disco, hemisféricas, oblongas, cónicas, cilíndricas, globulares y esféricas; los pesos del Tipo B, caracterizados por poseer aros de suspensión de hierro, pueden ser discoidales, esféricos, cónicos, bicónicos, hemisféricos, cilíndricos o en forma de bastoncillo; finalmente el Tipo $\mathrm{C}$ se reserva a las piezas que no presentan medios de suspensión, con pesas en forma de disco, esféricas, cónicas, enrolladas, bicónicas, hemisféricas, troncocónicas, rectangulares, poligonales y cilíndricas.

La variedad morfológica de las pesas es relativamente poco significativa comparada con la diversidad de tipos manifestada entre los contrapesos. Principalmente se conocen pesas de metal, en especial de plomo y de bronce, y pesas realizadas en piedra. Son frecuentes los ejemplares de plomo de forma troncocónica o cilíndrica así como los obtenidos por medio de verter plomo fundido en el interior de conchas de moluscos marinos de la clase cardium (Romualdi, 1989: 163; Corti, Pallante y Tarpini, 2001: 280-283, fig. 206). Un tipo específico lo constituyen las piezas de bronce huecas en forma de cuenco o taza - «pesi a 
ciotola» en italiano, «cup-weight» en inglés o «Kapselgewichte» en alemán- diseñadas para ser apiladas consecutivamente y que componen juegos de pesas calibradas (Glaser, 1999; Găzdac y Wright, 2009).

Para la fabricación de ponderales lapídeos se emplearon piedras duras de diversos tipos, generalmente de color negro u oscuro en los ejemplares menores, y mármoles o piedras locales en los de mayor tamaño. Se describen principalmente ejemplares esféricos truncados por sus polos o troncocónicos de base elíptica, algunos de ellos de tendencia ovalada en su sección vertical. Las pesas de mayor porte se dotaron de asas metálicas más o menos ornamentadas de bronce o hierro, que fueron fijadas a la pieza por medio de perforaciones selladas con plomo fundido. La corrección definitiva del peso de las piezas se manifiesta tanto en la eliminación de pequeñas porciones de su masa de piedra como en la adición de plomo (Corti, Pallante y Tarpini, 2001: 283-290), siendo frecuente que figure su valor ponderal inscrito en su cara superior. En las pesas más reducidas este valor se representó mediante símbolos correspondientes a la libra y sus submúltiplos y en las mayores por medio de numerales (Pontiroli, 1990: 178-187; Sutto, 2016: 291-298).

\section{CATÁLOGO}

Se presentan a continuación los elementos relacionados con instrumentos de pesar recuperados en las excavaciones llevadas a cabo en el yacimiento arqueológico de Segobriga. En primer lugar se relacionan los materiales correspondientes a mecanismos de balanzas y, a continuación, los contrapesos clasificados según sus sistemas de suspensión. Finalmente se detallan las pesas distinguiendo entre las que poseen y las que carecen de medios de aprehensión. Todas las piezas se custodian actualmente en el Museo de Segóbriga.

Su catalogación se estructura con los datos de procedencia de la pieza, contexto arqueológico y descripción morfológica. Para su clasificación se ha recurrido, siempre que ha sido posible, a la tipología establecida por Tyrrell en su estudio de los plomos del asentamiento britanorromano de Heybridge (Tyrrell, 2015).

\section{A. BalanZas De Brazos iguales (Fig. 2)}

1. Termas del Teatro (Área 2). Campaña 1982. No. de inv.: $183692=$ reg. arq.: 82/II/001.

Libra, balanza de brazos iguales de precisión provista de brazo graduado para contrapeso cursor.

Dimensiones: $18,2 \times 6,2 \times 0,4 \mathrm{~cm}$.

Pequeña balanza de bronce compuesta por una varilla recta de sección circular (scapus) que disminuye ligeramente de grosor hacia sus extremos. El brazo del que se suspende la pesa de contraste presenta una serie de once incisiones en su cara superior que dividen su longitud en doce segmentos de igual tamaño y que serviría como graduación para un contrapeso dotado de cursor para pesadas de precisión. A mitad de la cara superior del scapus presenta soldada perpendicularmente una lámina rectangular de escaso grosor que configura el fiel o iugum de la balanza al situarse entre las dos lengüetas del dispositivo de suspensión y disponer de una serie de tres pequeñas perforaciones que se alinean cuando el brazo alcanza la horizontalidad. El elemento de enganche (fulcrum) se fija al brazo mediante un pequeño vástago a modo de bisagra y se remata en su extremo superior, que es de sección circular, con una argolla en la que aún se conserva enroscado el primer eslabón de la cadena que la uniría al gancho de suspensión. Presenta una decoración anillada en la que se intercalan anillos gruesos entre pares de aros más finos disminuyendo en su diámetro hacia la parte más elevada de la pieza. A ambos extremos de los brazos se aprecian los orificios para la sujeción de los platillos que no se conservan. El correspondiente al brazo graduado está formado mediante la torsión de la propia varilla sobre sí misma hasta modelar un pequeño aro; el opuesto está constituido por una anilla circular soldada en su punta.

Se conserva en muy buen estado aunque ambos brazos se hallan algo doblados. Carece de gancho de suspensión y de platillos.

2. Foro. Pórtico Sur del Foro. Segunda galería y tabernae: Centro. Campaña 2003. N . de inv.: 112360 $=$ reg. arq.: 03-7500-001, punto de hallazgo 503 .

Procede de un contexto tardío de tierra arcillosa color marrón anaranjado con fragmentos de teja localizado en la segunda galería del pórtico meridional del foro a la altura de la denominada $4^{\mathrm{a}}$ taberna. Entre el material cerámico recuperado destaca un plato de cerámica paleocristiana gris de la forma Rigoir 1a, terra sigilla$t a$ clara $\mathrm{D}$ de la forma Hayes 59 y diversos fragmentos con decoración estampillada, terra sigillata hispánica tardía y cerámica pintada tardía.

Libra, balanza de brazos iguales.

Dimensiones: $16,5 \times 5,2 \times 0,3 \mathrm{~cm}$.

Balanza de bronce formada por un elemento vertical de suspensión (fulcrum) y un brazo horizontal móvil (scapus). El primero constituye una horquilla cuyo extremo superior se decora con cuatro esferas superpuestas y se remata con una argolla circular que conserva el primer eslabón de la cadena de unión con el gancho de suspensión. Dos largas lengüetas planas sirven para asir el brazo horizontal por medio de un vástago de sección circular del que pende un apéndice perforado soldado a su cara superior. El brazo está constituido por una varilla de sección circular ligeramente engrosada en su segmento central cuyos extremos presentan decoración anillada y se rematan con sendas argollas circulares (asae) que conservan las anillas de unión a las cadenas de suspensión de los platillos.

Se conserva en buen estado pese a que una de las lengüetas del dispositivo de suspensión se encuentra 


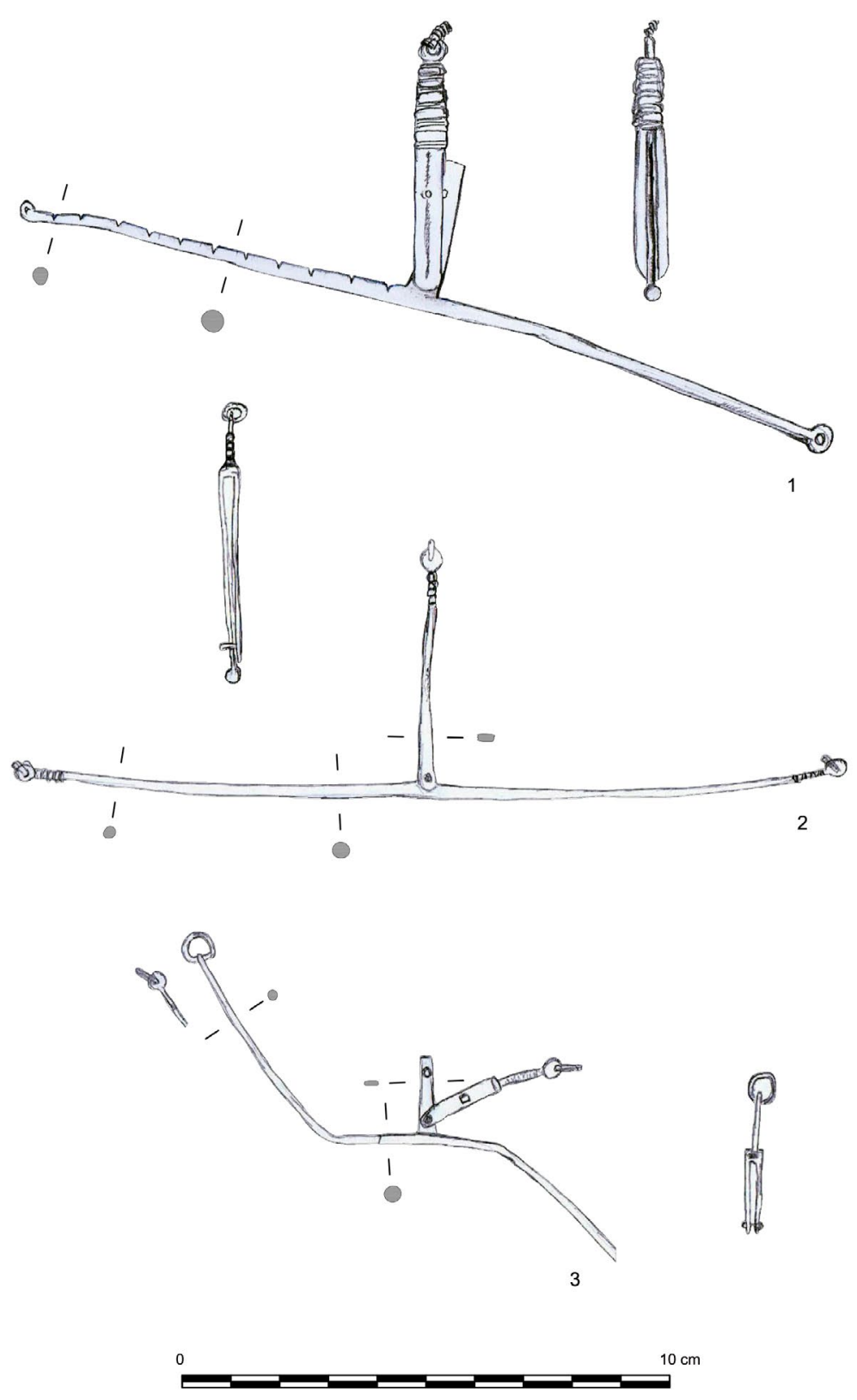

Figura 2: Balanzas halladas en Segobriga. El número de la pieza corresponde al del catálogo.

seccionada. No conserva platillos, cadenas ni gancho de suspensión.

3. Foro. Tabernae. Campaña 2003. $\mathrm{N}^{\circ}$. de inv.: $114240=$ reg. arq.: 03-7552-5, punto de hallazgo 735.

Recuperada en un nivel arcilloso de escasa potencia de color marrón ligeramente anaranjado en el interior de la denominada $2^{\mathrm{a}}$ taberna. Se fecha en época tardía por la presencia de terra sigillata hispánica tardía, principalmente de las formas Ritt. 8, Palol 8 y Drag. 37, y de cerámica pintada tardía, forma Abascal 21.

Libra, balanza de brazos iguales.

Dimensiones: 14,5 x 3,8 x 0,2 cm.
Balanza de bronce con dispositivo vertical de suspensión (fulcrum) y brazo horizontal móvil (scapus). El sistema de suspensión consiste en una horquilla muy simple con doble lengüeta plana y argolla de sección circular sin decoración. Se une al extremo inferior de una lámina rectangular soldada en perpendicular al brazo mediante un vástago circular que sirve de eje. Esta lámina funciona como fiel (iugum) al poseer una perforación que coincide con las otras dos existentes en las lengüetas cuando la balanza se equilibra. El brazo es una simple varilla de sección circular, ligeramente más gruesa en su segmento central, rematada en ambos extremos con dos aros en los que se conservan engarzadas sendas anillas.

El brazo se encuentra fraccionado en dos fragmentos. No conserva cadenas ni gancho de suspensión. Se 

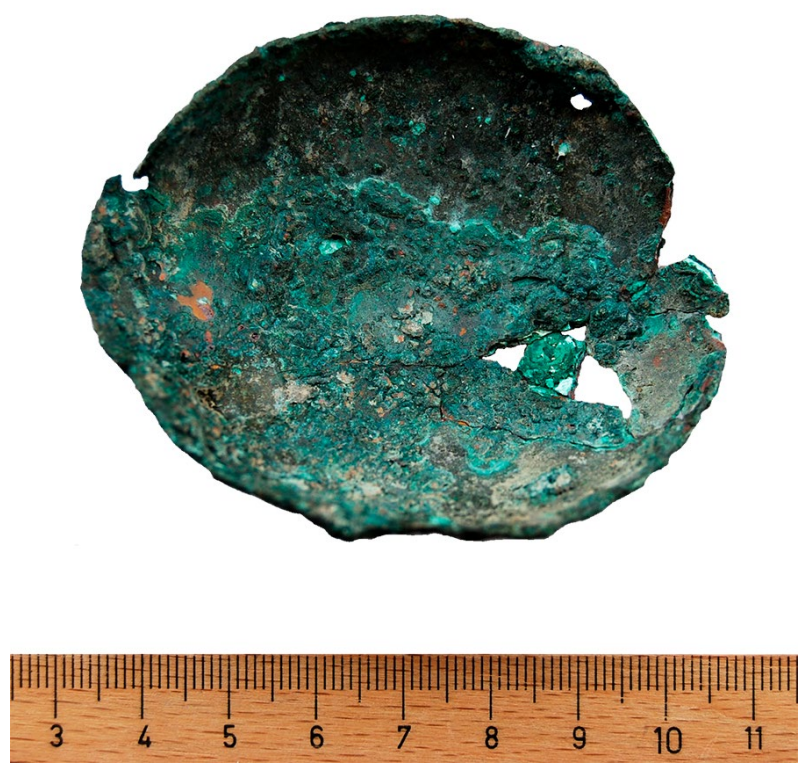

Figura 3: Plato de libra, $\mathrm{n}^{\circ} .4$ del catálogo.

vincula al platillo de balanza número 4 del presente catálogo pues fue recuperado en el mismo contexto.

4. Foro. Tabernae Campaña 2003. $\mathrm{N}^{\mathrm{o}}$. de inv.: 114237 $=$ reg. arq.: 03-7552-002, punto de hallazgo 671. (Fig. $3)$.

Recuperado en el mismo nivel tardío que la pieza $\mathrm{n}^{\circ}$. 3 del catálogo.

Lanx, plato de libra.

Diámetro: $6,5 \mathrm{~cm}$.

Platillo cóncavo de bronce de forma circular. Presenta tres pequeños orificios de suspensión perforados muy próximos al borde distribuidos de manera regular.

Se conserva fragmentado y con algunas lagunas, con uno de los orificios de suspensión rajado. Pátina verdosa de oxidación en ambas caras. Se vincula a la balanza $\mathrm{n}^{\circ} .3$ del presente catálogo al ser ambos recuperados en el mismo contexto.

\section{B. PESAS CON PERFORACIÓN DE SUSPENSIÓN ABIERTA EN EL PROPIO CUERPO DE LA PIEZA (Tipo A DE TyrRelL)}

5. Termas monumentales (exterior oeste). Campaña 1998. Cata XI. Sector A. Cuadrícula XIa. Nº. de inv.: $000034=$ reg. arq.: 98-100-032.

Hallado en un nivel superficial en el que la totalidad del material recuperado es de época altoimperial, con presencia de terra sigillata gálica, hispánica e hispánica brillante.

Contrapeso de statera. Tipo Tyrrell A3 (Figs. 4 y 5).

Dimensiones: 17,9 x 5,5 x 5,5 cm; diámetro en la base: $5,4 \mathrm{~cm}$.

Pesa fabricada en plomo de forma cilíndrica alargada con la base plana. Su superficie presenta numerosas vacuolas y una pátina homogénea de color blanquecino con áreas de oxidación amarronada. Incisión no original por golpe en un lateral, junto a la base, de 1,6 $\mathrm{cm}$ de longitud. En su extremo superior posee una anilla circular realizada también en plomo que abraza el cuerpo de la pesa. Es de sección oval, de 2,5 x 1,5 $\mathrm{cm}$, y delimita un orificio central irregular, de 1,5 $\mathrm{x}$ $1,7 \mathrm{~cm}$, en el que se aprecian restos de óxido de hierro separados $2 \mathrm{~cm}$ entre sí que, probablemente, corresponden al elemento de suspensión. Uno de sus lados se encuentra perfectamente fundido con la masa del contrapeso mientras que el opuesto presenta dos rebabas algo salientes.

Peso: $3.350 \mathrm{~g}$.

6. Los Enebrales (Saelices). N ${ }^{\circ}$ de inv.: 183687.

Colección privada. Procede de hallazgos realizados con detector de metales y, por tanto, descontextualizada arqueológicamente.

Pesa de telar. Tipo Tyrrell A3.

Dimensiones: $6,6 \times 2,8 \times 2,6 \mathrm{~cm}$.

Pesa de plomo de cuerpo troncopiramidal con la base cuadrada. Posee una perforación circular de suspensión de $0,7 \mathrm{~cm}$ de diámetro en el extremo superior. Presenta su superficie lisa con áreas de oxidación amarronada.

Peso: $321 \mathrm{~g}$.

7. Circo. Campaña 2005. №. de inv.: $127046=$ reg. arq.: 05-9000-113.

Recuperada en niveles superficiales del circo.

Pesa de telar. Tipo Tyrrell A3.

Dimensiones: 5,6 x 1,5 x $1,5 \mathrm{~cm}$.

Pesa de plomo de cuerpo troncopiramidal con las aristas redondeadas. Sección cuadrangular en la parte inferior y rectangular aplanada en la superior. Presenta un orificio de sección circular en el extremo superior, de $0,5 \mathrm{~cm}$ de diámetro, y en la cara inferior un rebaje ovoide, de $1 \mathrm{~cm}$ de longitud. Superficie áspera con la mitad superior oxidada en tonos amarronados.

Peso: $86,9 \mathrm{~g}$.

8. Circo. Campaña 2006. $\mathrm{N}^{\mathrm{o}}$. de inv.: $144440=$ reg. arq.: 06-9400-001, punto de hallazgo 081.

Hallada en el nivel de horizontalización de la arena del circo junto al graderío norte en el espacio ocupado previamente por el denominado ustrinum colectivo de la necrópolis noroccidental. Se trata de un relleno de tierra marrón oscura de textura granulosa y compacidad media.

Pesa de telar. Tipo Tyrrell A3.

Dimensiones: $4,4 \mathrm{~cm}$ de altura. Sección cuadrada: extremo inferior, 1,7 cm; extremo superior, $1,0 \mathrm{~cm}$.

Pesa de plomo de desarrollo troncopiramidal de base cuadrada y aristas curvadas. Perforación de suspensión de $0,2 \mathrm{~cm}$ de anchura en el extremo superior. Su cara 

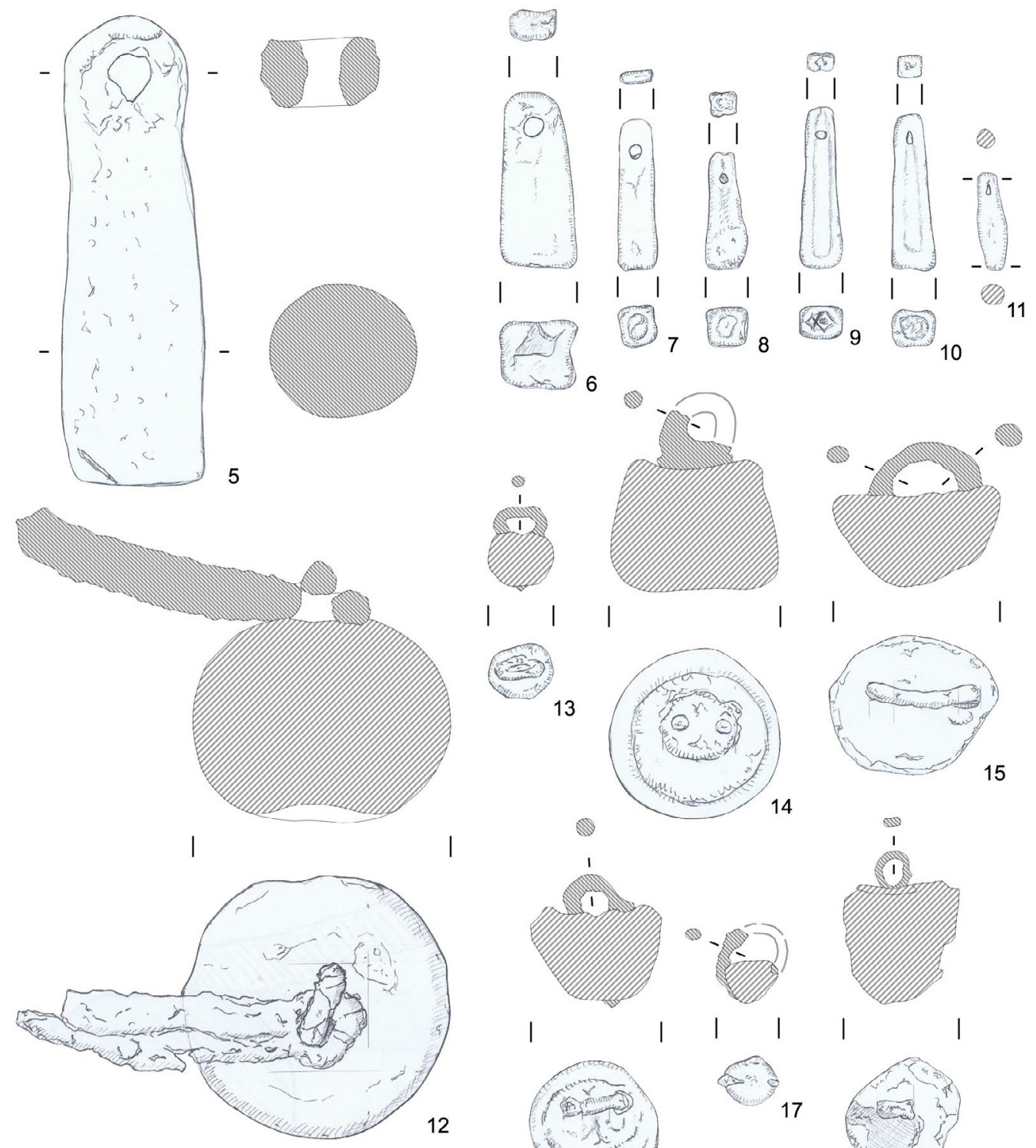

\section{।}
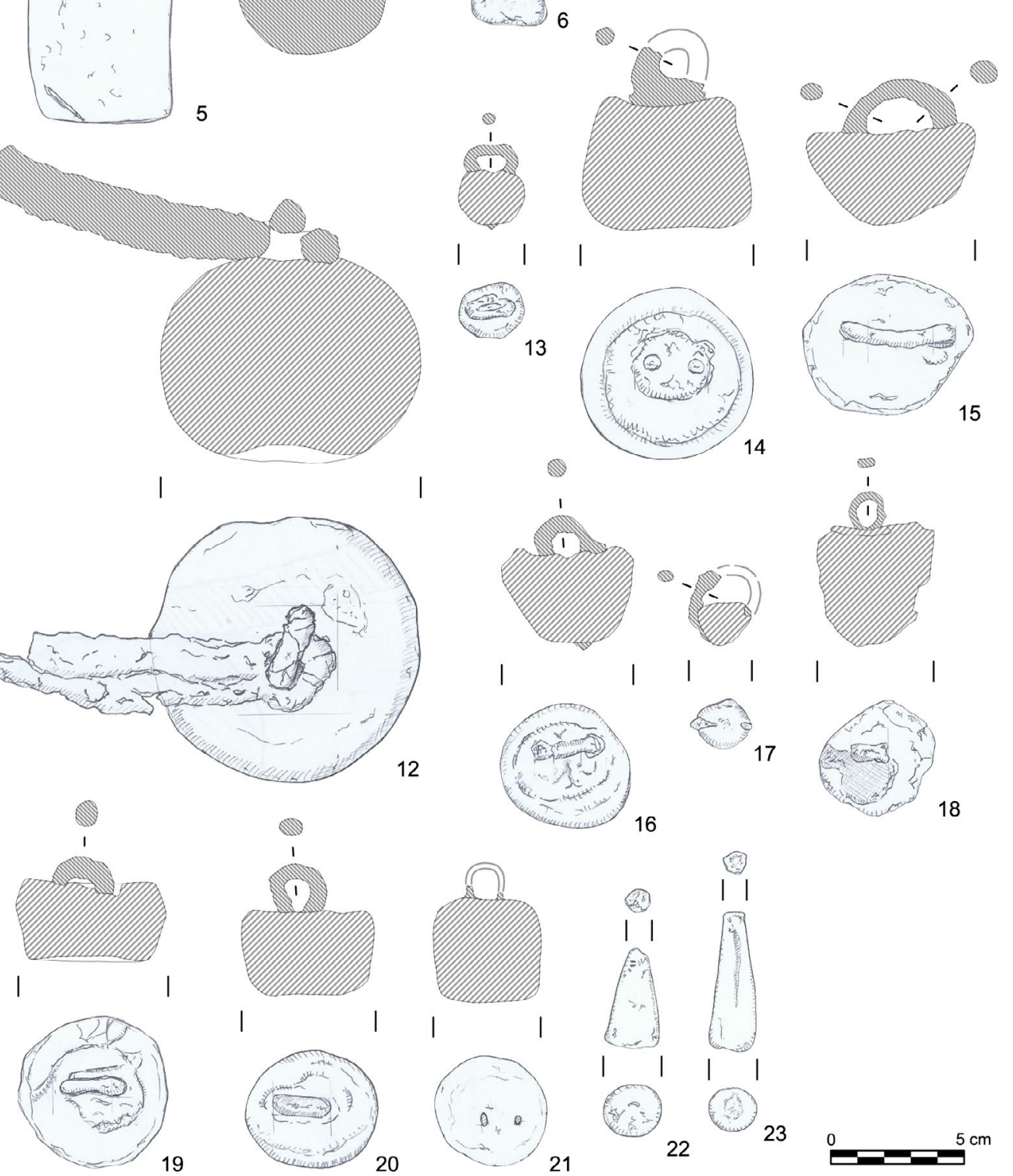

Figura 4: Dibujo de las pesas y contrapesos de Segobriga y su entorno. El número de la pieza corresponde al del catálogo.

superior es lisa y en la inferior se aprecia un rebaje de forma ovalada. Sus cuatro caras principales presentan acanaladuras poco profundas que recorren longitudinalmente la totalidad de los planos. Superficie lisa con escasos golpes.

Peso: 69,6 g.
9. Criptopórtico junto a las Termas del Teatro. Campaña 2009. UE 13309. Campaña 2009. $\mathrm{N}^{\circ}$. de inv.: $175465=$ reg. arq.: 09-13309-010, punto de hallazgo 076.

Recuperada en una nivelación fechada en época flavia compuesta por tierra arenosa de color beige, que 

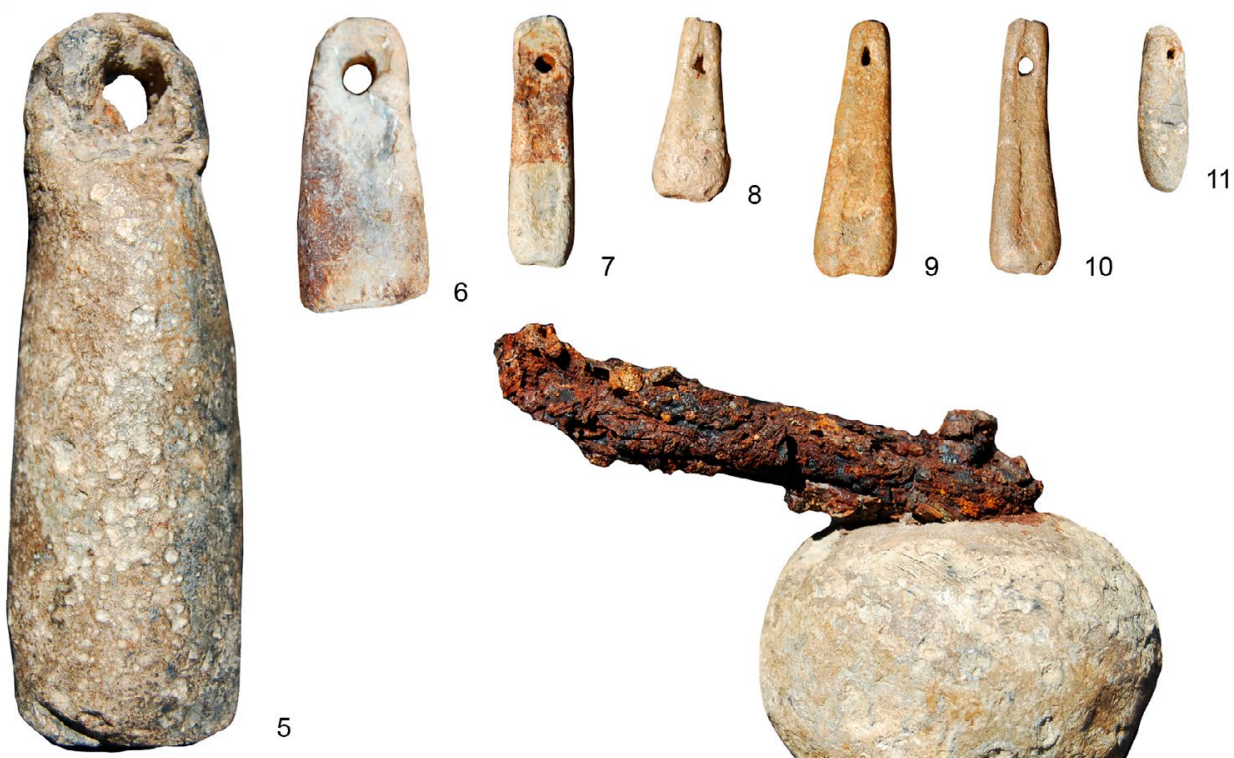

6
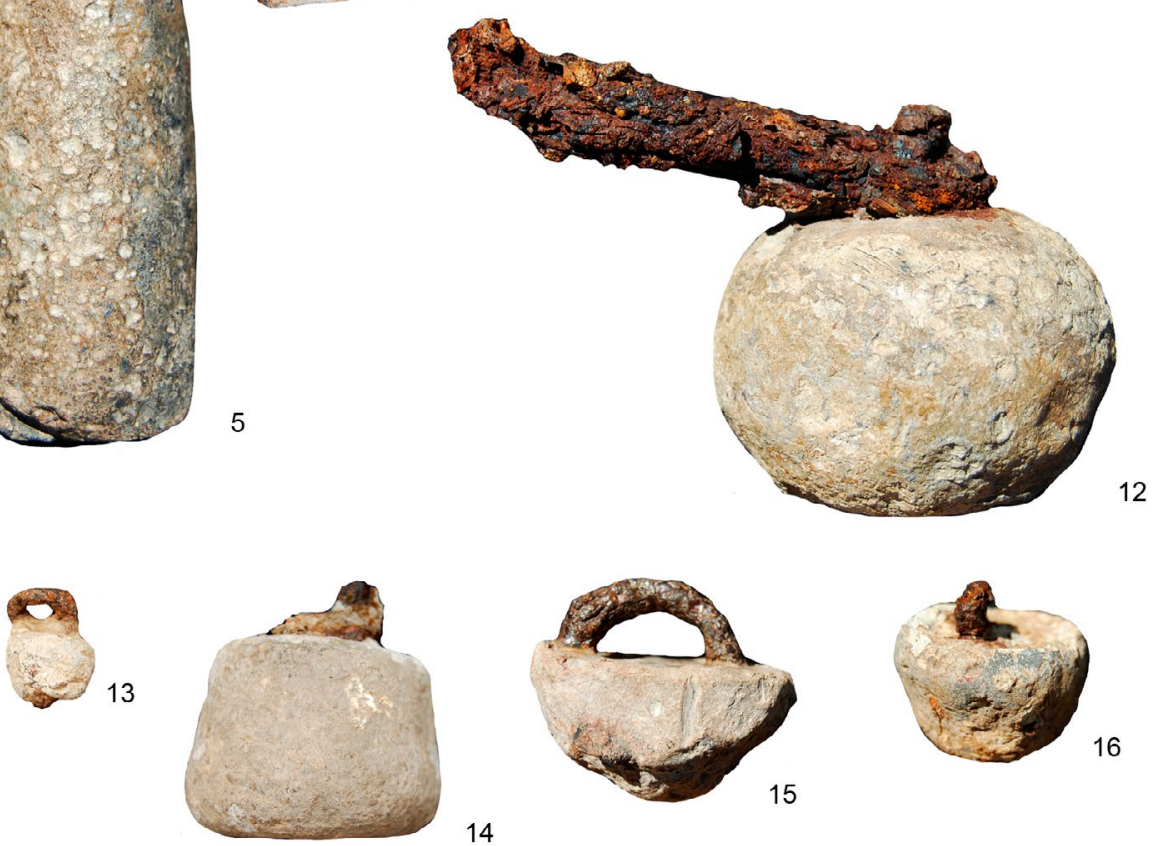

14
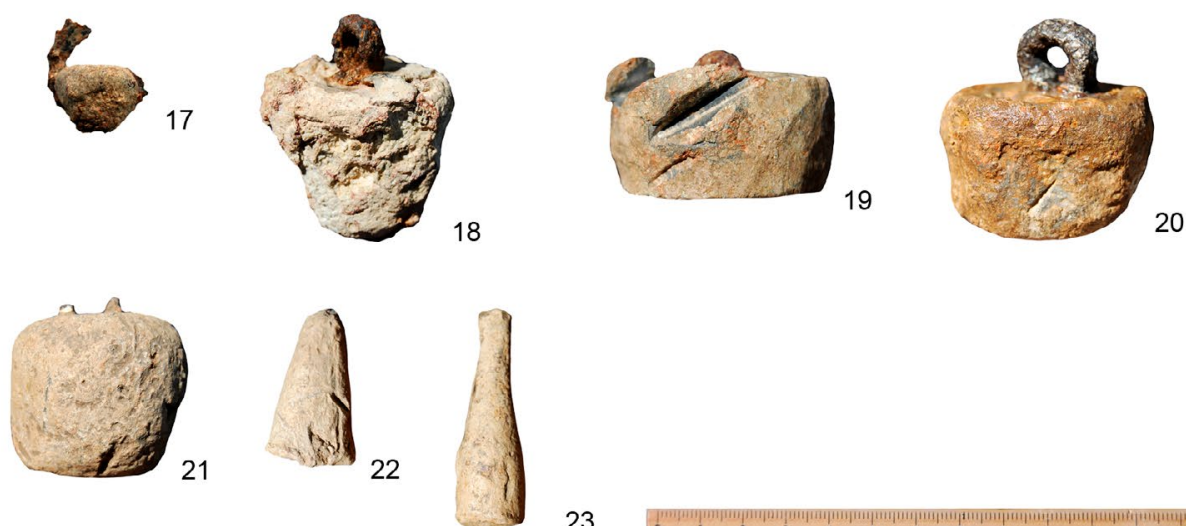

23

Figura 5: Pesas y contrapesos de Segobriga y su entorno. El número de la pieza corresponde al del catálogo.

contenía abundante cerámica, fragmentos de adobes, tegulae troceadas, ladrillos romboidales, placas de enlucido parietal, fauna y escasas piedras de pequeño tamaño. Presencia, entre otras producciones, de terra sigillata itálica, gálica e hispánica, paredes finas, lucernas, fuentes de engobe interno rojo pompeyano, ánforas vinarias de producción tarraconenese y salsarias de la Bética y dos pesas cerámicas de telar.

Pesa de telar. Tipo Tyrrell A3.

Dimensiones: $5,9 \mathrm{~cm}$ de altura. Sección cuadrada: extremo inferior, 1,9 cm; extremo superior $1,0 \mathrm{~cm}$.

Pesa troncopiramidal de plomo de base cuadrada y aristas redondeadas. Perforación de suspensión de forma triangular en el extremo superior de $0,5 \mathrm{~cm}$ longitud y $0,3 \mathrm{~cm}$ de base. Las cuatro caras principales presentan acanaladuras longitudinales poco profundas y la base un rebaje circular. $\mathrm{Su}$ superficie es uniforme y lisa, con un único rasguño en la zona de la base.

Peso: $110,4 \mathrm{~g}$.

10. Criptopórtico junto a las Termas del Teatro. Campaña 2009. $\mathrm{N}^{\mathrm{o}}$. de inv.: $175464=$ reg. arq.: 0913266-007, punto de hallazgo 55.

Se halló en el interior de una zanja de expolio fechada en época visigoda rellena de tierra arenosa oscura con numerosas piedras medianas y grandes y abundantes 
fragmentos de imbrex y tegula. La datación del contexto se establece por la presencia en el relleno de ollas de borde triangular junto a producciones de cronología anterior procedentes de los niveles preexistentes.

Pesa de telar. Tipo Tyrrell A3.

Dimensiones: $6 \mathrm{~cm}$ de altura. Sección rectangular: extremo superior, $1,7 \times 1,4 \mathrm{~cm}$; extremo inferior: $1,0 \mathrm{x}$ $0,8 \mathrm{~cm}$.

Pesa de forma troncopiramidal fabricada en plomo con agujero de suspensión circular de $0,3 \mathrm{~cm}$ de diámetro en el extremo superior. Presenta dos acanaladuras relativamente profundas que recorren longitudinalmente las caras frontal y trasera donde se sitúa la perforación de enganche y una muesca en forma de aspa en la base. Superficie ligeramente áspera con pátina amarillenta. Peso: $76,3 \mathrm{~g}$.

\section{Los Enebrales. $\mathrm{N}^{\mathrm{o}}$ de inv.: 183688}

Colección privada. El contexto de hallazgo es el mismo que la pieza $n^{\circ} .6$ del catálogo.

Pesa de telar o contrapeso de precisión para una libra de brazo graduado. Tipo Tyrrell A6; tipo Corti et al. «forma di bastoncello».

Dimensiones: $3,7 \mathrm{~cm}$ de altura. Sección circular: diámetro máximo: $1,1 \mathrm{~cm}$; diámetro en la base, $0,8 \mathrm{~cm}$.

Pequeña pesa de plomo en forma de bolo irregular. Presenta una perforación de suspensión en el extremo superior de sección triangular $(4,1 \times 1,7 \mathrm{~cm})$. Superficie básicamente lisa con algunas rozaduras.

Peso: $30 \mathrm{~g}$.

C. Pesas dotadas de un anillo de SUSPENSión INDEPENDIENTE DE LA PIEZA INSERTO EN LA MASA DE PLOMO (Tipo B DE TyrRell)

12. Criptopórtico junto a las Termas del Teatro. Campaña 2009. No. de inv.: 175467 = reg. arq.: 0913338-002, punto de hallazgo 74.

Recuperado en un relleno de tierra suelta y arenosa, de color marrón, con piedras medianas y fragmentos de teja curva, que amortizaba un silo de época tardovisigoda.

Contrapeso de statera. Tipo Tyrrell B2.

Dimensiones de la pesa de plomo: $7,5 \mathrm{~cm}$ de altura; 10 $\mathrm{cm}$ de diámetro máximo; $7 \mathrm{~cm}$ de diámetro en la base. Argolla de suspensión: diámetro máximo, $3,3 \mathrm{~cm}$; sección circular de 1,4 cm de diámetro. Eslabón: 13,5 x $3,8 \times 2,6 \mathrm{~cm}$.

Pesa de plomo en forma de esferoide achatado con la base convexa. Superficie muy blanquecina con numerosas burbujas. Conserva una argolla de hierro de sección circular embutida en la masa del plomo en la que se empalma un eslabón alargado de hierro fragmentado por su extremo distal. En la pared de la pesa y junto al asa de hierro, en posición oblicua, presenta seis trazos verticales incisos a los que sigue la letra $\mathrm{S}$, abreviatura

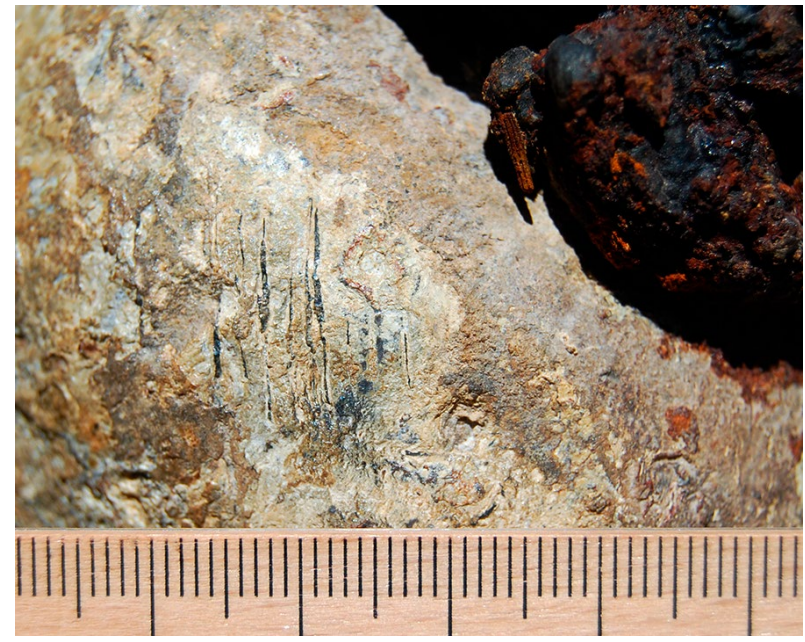

Figura 6: Indicación ponderal en el contrapeso de statera, $\mathrm{n}^{\mathrm{o}}$. 12 del catálogo.

de semis, que alude al peso del contrapeso expresado en libras. Altura de las letras: 1,8 cm. S: 1,5 cm. (Fig. 6). Peso: $4.875 \mathrm{~g}$.

13. Los Enebrales. $N^{o}$ de inv.: 183689.

Colección privada. El contexto de hallazgo es el mismo que las piezas $\mathrm{n}^{\mathrm{o}} .6 \mathrm{y} \mathrm{n}^{\mathrm{o}}$. 11 del catálogo.

Contrapeso de precisión para una libra de brazo graduado. Tipo Tyrrell B2.

Dimensiones de la pesa de plomo: 2,2 cm de altura y 2,5 cm de diámetro máximo. Anillo de suspensión: 2,0 x 2,2 cm; sección circular de 0,3 cm de diámetro.

Pequeña pesa de plomo de forma globular. Superficie bastante irregular con espesa pátina blanquecina. Presenta un anillo de suspensión achatado que está formado por un vástago de hierro de sección circular insertado en la bola de plomo y retorcido sobre sí mismo para formar un aro. Su extremo se manifiesta en la base de la pesa.

Peso: $57 \mathrm{~g}$.

14. Decumano entre las termas del teatro y el foro. Campaña 1983. $\mathrm{N}^{\circ}$. de inv.: $018364=$ reg. arq.:

Cuadrícula III-Nivel 1, no 192.

Contrapeso de statera. Tipo Tyrrell B3.

Dimensiones de la pesa de plomo: $4,6 \mathrm{~cm}$ de altura; $6,5 \mathrm{~cm}$ de diámetro en la base y $5,0 \mathrm{~cm}$ de diámetro en la cara superior. Cáncamo de suspensión: $2,5 \mathrm{~cm}$ anchura y 2,2 cm de altura conservada; sección circular de $0,6 \mathrm{~cm}$ de diámetro.

Pesa de plomo de cuerpo troncocónico poco desarrollado y superficie rugosa de color blanquecino. Su extremo superior se encuentra ligeramente rebajado en un diámetro de $3,4 \mathrm{~cm}$ para la inserción de un cáncamo de suspensión de hierro del que solo se conserva su mitad inferior. Base plana ligeramente cóncava. Presenta un golpe en uno de sus laterales.

Peso: $1.348 \mathrm{~g}$. 
15. Costado occidental del foro y kardo máximo. Campaña 2003. $\mathrm{N}^{\mathrm{o}}$. de inv.: $103908=$ reg. arq.: 037290-022, punto de hallazgo 325 .

Procede de un nivel rojizo de derrumbe semi-compacto con muchas tejas y piedras. Se fecha en época tardoantigua por la presencia de cerámica de cocina tardía, un fragmento de botella Abascal 21 y una moneda de Arcadio. En este nivel se recuperaron también un plato de costillas y una olla de bronce.

Contrapeso de statera. Tipo Tyrrell B5.

Dimensiones de la pesa de plomo: $3,5 \times 6,2 \times 5,5 \mathrm{~cm}$. Anilla de suspensión: 2,0 x 4,1 cm; sección circular de 0,8-0,9 $\mathrm{cm}$ de diámetro.

Pesa de plomo de forma hemisférica algo irregular con el extremo superior plano que presenta dos pequeños rebajes redondeados. Anilla de suspensión de hierro de sección circular alojada hasta su mitad en la masa de plomo. Superficie blanquecina y rugosa con vacuolas. Muestra un golpe moderno y dos incisiones laterales que arrancan desde la cara superior. Miden 1,7 y $0,7 \mathrm{~cm}$ de longitud respectivamente y están separadas entre sí $1,9 \mathrm{~cm}$.

Peso: $562 \mathrm{~g}$.

16. Foro. Tabernae. Campaña 2003. $\mathrm{N}^{\mathrm{o}}$. de inv.: $114242=$ reg. arq.: 03-7552-007, punto de hallazgo 739.

Recuperado en un nivel arcilloso de color marrón y escasa potencia, ligeramente anaranjado y de compacidad media, que cubría el pavimento de la denominada $2^{\text {a }}$ taberna. Contexto fechado hacia los siglos IV-V d.C. por la presencia de terra sigillata hispánica tardía de las formas Ritt. 8, Palol 8 y Drag. 37 y cerámica pintada tardía, forma Abascal 21.

Contrapeso de statera. Tipo Tyrrell B5.

Dimensiones de la pesa de plomo: 3,6 x 5 x 4,6 cm. Anilla de suspensión: 1,3 x 2,2 cm; sección circular de $0,7 \mathrm{~cm}$ de diámetro.

Pesa de plomo de forma hemisférica y aristas redondeadas. Superficie muy rugosa con una gruesa pátina blanquecina, especialmente en la cara superior. Muestra un rebaje circular de $3,4 \mathrm{~cm}$ de diámetro en el plano superior coincidente con la inserción del cáncamo de suspensión, formado por un vástago de hierro de sección circular curvado sobre sí mismo cuyo extremo se aprecia en la base de la pesa.

Peso: $431 \mathrm{~g}$.

17. Los Enebrales. $\mathrm{N}^{\circ}$ de inv.: 183690.

Colección privada. El contexto de hallazgo es el mismo que las piezas $\mathrm{n}^{\circ} .6, \mathrm{n}^{\circ} .11 \mathrm{y} \mathrm{n}^{\circ} .13$ del catálogo.

Contrapeso de precisión para una libra de brazo graduado. Tipo Tyrrell B5; tipo Corti, Pallante y Tarpini «a cestello».

Dimensiones de la pesa de plomo: 1,6 × 2,0 x 1,8 cm. Anilla de suspensión: $2,7 \mathrm{~cm}$ de altura conservada y
2,3 cm de anchura máxima; sección ovalada de $0,6 \mathrm{x}$ $0,4 \mathrm{~cm}$.

Pequeña pesa de plomo de forma cónica invertida con las aristas muy redondeadas. Superficie muy rugosa y con áreas de oxidación de color marrón oscuro. Conserva la mitad de una anilla de suspensión de hierro de sección ovalada que arranca de los laterales de la pieza y se desarrolla ampliamente por encima de la misma en forma de asa de cesta.

Peso: $30 \mathrm{~g}$.

18. Foro. Tabernae. Campaña 2003. $\mathrm{N}^{\mathrm{o}}$. de inv.: $113209=$ reg. arq.: 03-7518-033, punto de hallazgo 562.

Hallado en la denominada $5^{\text {a }}$ taberna, situada en el costado meridional del foro junto al pórtico sur, sobre el pavimento de mosaico (UE 7530), en un nivel de tierra de color anaranjado de textura arcillosa con fragmentos de teja, que lo amortizaba. El contexto se fecha a fines del siglo IV o a inicios del siglo $\mathrm{V}$ d.C. destacando entre los materiales recuperados una importante cantidad de monedas con presencia de un ejemplar de Arcadio y diversos fragmentos de terra sigillata hispánica tardía de las formas Drag. 37b, botellas de cerámica pintada, forma Abascal 21, y lucernas africanas de la forma Atlante VIII. También de este nivel procede un fragmento de botella de vidrio con dos asas, forma Isings 129.

Contrapeso de statera. Tipo Tyrrell B7.

Dimensiones de la pesa de plomo: 4,6 × 5 × $4 \mathrm{~cm}$. Cáncamo de suspensión: 1,5 x 1,4 cm; sección aplanada de $0,6 \times 0,3 \mathrm{~cm}$

Pesa de forma cónica invertida fabricada en plomo. Superficie blanquecina muy irregular y rugosa, con vacuolas. Presenta una incisión antigua en uno de sus laterales. En la cara superior se aprecia una capa irregular de plomo vertida sobre la pesa en torno al cáncamo de suspensión, que es de hierro y forma una fina anilla circular de sección aplanada. En el extremo inferior se aprecian evidencias de oxidación de este vástago de hierro.

Peso: $363 \mathrm{~g}$.

19. Basílica del Foro. Campaña 2004. $N^{o}$. de inv.: $119718=$ reg. arq.: 04-7728-129: punto de hallazgo 281.

Se halló en un nivel superficial, interpretado como de terreras antiguas, compuesto por tierra gris ligeramente anaranjada, arenosa, con piedras de pequeño y medio tamaño y fragmentos de teja. Presencia de cerámica de época emiral junto a un conjunto bastante homogéneo de mitad del siglo $\mathrm{V}$, formado por terra sigillata hispánica tardía, ánfora africanas de época vándala Keay LXI y XXV y cerámica común,y varios fragmentos residuales de época altoimperial.

Contrapeso de statera. Tipo Tyrrell B8. 
Dimensiones de la pesa de plomo: $2,8 \mathrm{~cm}$ de longitud, $5,0 \mathrm{~cm}$ de diámetro inferior y $5,1 \mathrm{~cm}$ de diámetro superior. Anilla de suspensión: 0,8 x $2,5 \mathrm{~cm}$; sección circular de $0,8 \mathrm{~cm}$ de diámetro.

Pesa de plomo de desarrollo cilíndrico con las aristas redondeadas. Superficie lisa y regular de apariencia espatulada, algo más rugosa y con vacuolas en la base, con una pátina homogénea de color blanquecino. Extremo superior plano algo rehundido en su centro, mostrando un rebaje circular de $3 \mathrm{~cm}$ de diámetro en torno a la anilla de suspensión que es de hierro y de sección circular. Base plana ligeramente cóncava. Presenta una incisión poco marcada de 2,1 $\mathrm{cm}$ de longitud en un lateral y otras dos muy marcadas, que parecen corresponder a sendos golpes de herramienta tal vez producidos en el momento del hallazgo. Se sitúan en la arista con la cara superior y en el lateral.

Peso: $606 \mathrm{~g}$.

20. Pórtico Sur del Foro. Segunda galería y tabernae. Campaña 2003. No. de inv.: 104041 = reg. arq.: 037301-001, punto de hallazgo 202.

Hallado en un nivel de tierra gris suelta y granulosa fechado en el siglo IX, localizado bajo estructuras de reocupación de época medieval en la zona más cercana a la basílica del foro.

Contrapeso de statera. Tipo Tyrrell B8.

Dimensiones pesa de plomo: 3,1 cm de longitud, 3,3 $\mathrm{cm}$ de diámetro inferior y $4,6 \mathrm{~cm}$ de diámetro superior. Anilla de suspensión: 1,7 x 2,3 cm; sección circular de $0,9 \mathrm{~cm}$ de diámetro.

Pesa de plomo de cuerpo cilíndrico con las aristas redondeadas. Superficie rugosa con vacuolas y pátina de color ocre amarillento. La cara superior presenta un rebaje de $3,5 \mathrm{~cm}$ de diámetro en cuyo centro se inserta un vástago de suspensión de hierro en forma de lazo de sección circular. Base ligeramente convexa.

Peso: $481 \mathrm{~g}$.

21. Decumano entre las termas del teatro y el foro.

Campaña 1983. No. de inv.: $018512=$ reg. arq.:

83-Cuadrícula III-Nivel 2, nº 327.

Contrapeso de statera. Tipo Tyrrell B8.

Dimensiones de la pesa de plomo: $4 \mathrm{~cm}$ de longitud, $3,5 \mathrm{~cm}$ de diámetro inferior y $4,0 \mathrm{~cm}$ de diámetro superior. Anilla de suspensión: anchura: $1,8 \mathrm{~cm}$; sección ovalada de $0,4 \times 0,2 \mathrm{~cm}$.

Pesa de plomo de forma cilíndrica con las aristas redondeadas. Superficie rugosa con una pátina homogénea de color blanquecino que presenta diversos golpes e incisiones, uno en la base y tres en el lateral. Conserva únicamente los arranques de una fina anilla de suspensión de hierro de sección ovalada.

Peso: $466 \mathrm{~g}$.
D. Pesas Que no PResentan Medios de SuSPensión (TIPO TYRRELl C)

22. Circo. Campaña de 2005 . $\mathrm{N}^{\mathrm{o}}$. de inv.: $134732=$ reg. arq.: 05-9184-723.

Procede de un nivel superficial situado al exterior del graderío sur del circo, compuesto por tierra compacta de color gris oscuro con restos orgánicos de la cubierta vegetal. Presencia de piedras de pequeño tamaño, material de construcción y fragmentos de cerámica de cronología dispar, desde época altoimperial hasta época contemporánea.

Pesa de libra, balanza de brazos iguales. Tipo Tyrrell C3.

Dimensiones: $3,7 \mathrm{~cm}$ de altura, $2,1 \mathrm{~cm}$ de diámetro inferior y $1,0 \mathrm{~cm}$ de diámetro superior.

Pesa cónica de plomo de base algo curvada y aristas vivas. Superficie blanquecina y rugosa con algunas vacuolas. Presenta dos muescas oblicuas en la mitad inferior. Peso.: $70,7 \mathrm{~g}$.

23. Circo. Campaña de 2006. $\mathrm{N}^{\mathrm{o}}$. de inv.: $140795=$ reg. arq.: 06-9343-187, punto de hallazgo 064.

Hallada en un nivel superficial en la excavación del graderío norte del circo, formado por tierra color marrón de textura granulosa y compacta. Predomina el material cerámico de época altoimperial pero hay presencia de fragmentos de época andalusí y moderna.

Pesa de libra, balanza de brazos iguales. Tipo Tyrrell C3.

Dimensiones: $5,2 \mathrm{~cm}$ de altura, $1,8 \mathrm{~cm}$ de diámetro inferior y $0,9 \mathrm{~cm}$ de diámetro superior.

Pesa de plomo de forma troncocónica irregular con la base algo redondeada y el extremo superior alargado. Pátina blancuzca en toda su superficie. Presenta dos incisiones contrapuestas poco profundas con rebaba lateral.

Peso.: $81,4 \mathrm{~g}$.

\section{E. Pesas PROVISTAS DE MEDIOS DE APREHENSIÓN}

24. Foro. Plaza. Campaña 2001. Nº de inv.: 065932 $=$ reg. arq.: 01-5000-1786.

Procede de un nivel vegetal superficial de tierra marón oscura con abundantes raíces.

Pesa de libra, balanza de brazos iguales. (Fig. 7).

Diámetro: $2,6 \mathrm{~cm}$.

Pequeña pesa de bronce de forma troncocónica circular. Base plana con reborde engrosado delimitado por línea incisa. Cara superior con disco central rehundido para fijación de un elemento de aprehensión formado por una pequeña esfera ligeramente achatada.

Pátina verde oscura en toda la superficie de la pieza. Peso.: $28 \mathrm{~g}$. 

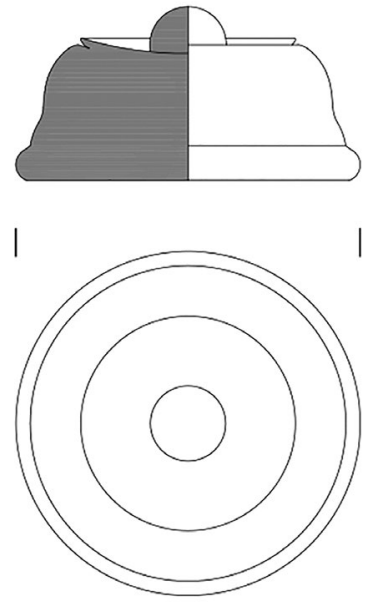

O $3 \mathrm{~cm}$

Figura 7: Pesa de bronce de una libra, nº 24 del catálogo.

25. La pieza se conserva en el Museo de Segóbriga desde la década de los años 70 del siglo XX con la única referencia de que procede de Huete. $\mathrm{N}^{\circ}$. de inv.: 183691.

Pesa de libra. (Fig. 8).

Dimensiones: $12,7 \times 22,45 \times 17,50 \mathrm{~cm}$; asa: $3,8 \times 15,3$ $\mathrm{x} 1,2 \mathrm{~cm}$.

Gran pesa de piedra caliza blanca de sección ovalada con el extremo superior achatado y plano. Superficie
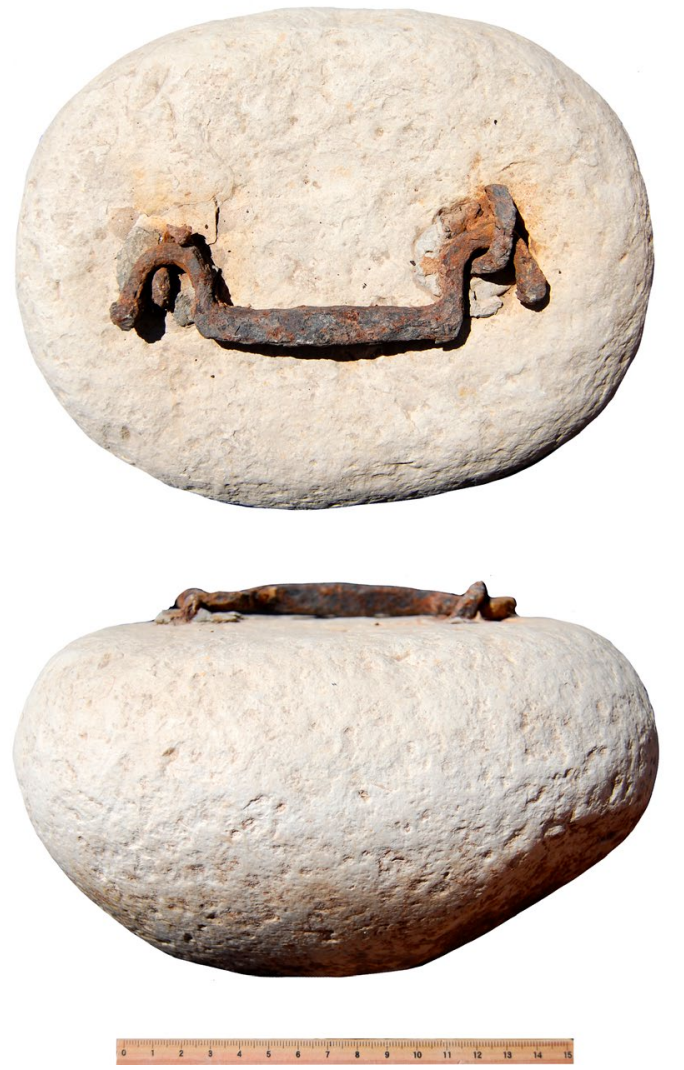

Figura 8: Pesa de libra procedente de Huete, $\mathrm{n}^{\circ} .25$ del catálogo.

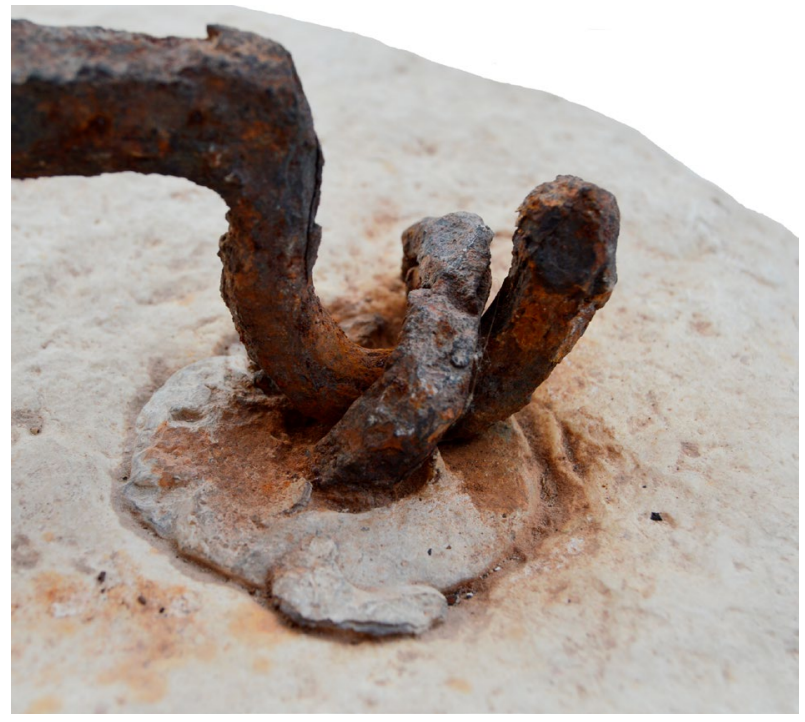

Figura 9: Detalle de la fijación del asa en la pesa de Huete, $n^{\circ}$. 25 del catálogo.

alisada con irregularidades poco profundas. Presenta uno de los laterales largos algo deformado como si hubiera perdido parte de la masa en su desarrollo curvo. En la cara superior conserva un asa de hierro que forma una fracción central recta de sección cuadrada y sendos ganchos en $\mathrm{U}$ de sección redondeada rematados en sus extremos por engrosamientos esféricos. Se une al cuerpo de la pesa mediante dos argollas de hierro en forma de cáncamos anclados con plomo en el interior de dos perforaciones dispuestas en su eje longitudinal (Fig. 9). No presenta marcas incisas.

Peso: $13.400 \mathrm{~g}$

\section{CONCLUSIONES}

El conjunto de materiales presentado revela en primer lugar que los restos relativos a staterae se reducen a sus contrapesos estando ausentes los otros componentes que integran esta clase de balanzas. Por el contrario, se han identificado tres librae que se conservan prácticamente completas a excepción de sus platillos, tratándose en todos los casos de ejemplares de pequeño tamaño destinados a pesadas de precisión. $\mathrm{La}$ balanza $\mathrm{n}^{\circ} .1$ del presente catálogo pertenece al tipo dotado de brazo graduado para la disposición de un contrapeso cursor que permite aquilatar la medición. En él presenta once incisiones equidistantes que dividen el brazo en doce segmentos de igual tamaño correspondientes a las doce subdivisiones de la libra en unciae (Corti, Pallante y Tarpini, 2001: 272). Los pequeños contrapesos catalogados con los $\mathrm{n}^{\circ} .11, \mathrm{n}^{\mathrm{o}} .13 \mathrm{y}$ $\mathrm{n}^{\mathrm{o}} .17$ corresponden a este tipo de balanzas aunque su hallazgo fuera de la ciudad impide relacionarlos con este ejemplar.

Estos tres contrapesos fueron hallados con detector de metales en una zona elevada al noreste de $\mathrm{Se}$ gobriga, al pie de la vía Carthago Nova-Complutum, 
conocida con el topónimo Los Enebrales, junto con un lote de 214 proyectiles de plomo asignables tipológicamente a los enfrentamientos bélicos del primer tercio del siglo I a. C. en el solar hispano (Cebrián, 2014). $\mathrm{Su}$ presencia en este contexto puede relacionarse así con el pesado del plomo para la realización de los proyectiles. Estos pequeños aequipondia se asemejan formalmente a los procedentes de Ariano di Castelvetro (Corti, Pallante y Tarpini, 2001: 302, fig. 222,7) y de Sant'Ambrogio (Corti, Pallante y Tarpini, 2001: 304, fig. 223,5 a 9).

La balanza $\mathrm{n}^{\circ}$. 1 cuenta además con un sistema de verificación de la horizontalidad del brazo compuesto por una lámina perpendicular perforada dispuesta entre las dos lengüetas del fulcrum que también están perforadas. Mientras la balanza $n^{\circ}$. 3 dispone de un fiel muy similar aunque carece del dispositivo de aproximación y la $\mathrm{n}^{\circ} .2$ es aún más simple en su mecanismo, pues no presenta ni fiel ni escala graduada. El único platillo catalogado, $\mathrm{n}^{\circ}$. 4 , se relaciona funcionalmente con la libra $\mathrm{n}^{\mathrm{o}}, 3$ pues ambos proceden del mismo nivel estratigráfico localizado en el interior de la denominada $2^{\mathrm{a}}$ taberna situada al sur del pórtico meridional del foro. Morfológicamente emparenta con un lanx procedente de Regina Turdulorum en Badajoz cuyo diámetro es ligeramente más reducido (Pozo, 2002: 102, fig. 100).

Se trata de balanzas de carácter eminentemente práctico con decoraciones muy sobrias de tipo anillado restringidas a la parte superior del fulcro (librae $\mathrm{n}^{\circ}$. $1 \mathrm{y} \mathrm{n}^{\mathrm{o}}$. 3) o al fulcro y al extremo de los brazos (libra $n^{\circ}$. 2). Se relacionan, en general, con transacciones comerciales al por menor de productos selectos y delicados - cambistas- o a actividades artesanales de precisión -orfebrería, joyería- o que requieren del control preciso de sus componentes como la elaboración de preparados (Daremberg y Saglio, 1900: 1225-1226).

Las balanzas con brazo graduado son relativamente inusuales. Daremberg y Saglio (1900: 1226, fig. 4472) recogen tres ejemplares, uno procedente de Pompeya y depositado en el Museo de Nápoles, otro del Pergamonmuseum en Berlín y un tercero del $\mathrm{Mu}$ seo Británico. Se han publicado también piezas del conjunto arqueológico-natural de Santomé custodiada en el Museo Arqueolóxico Provincial de Ourense (Rodríguez González, 2010), de las excavaciones de Conimbriga (Alarçao y Étienne, 1979: 175; Ponte, 1979:129-130 n 2-5, Est. I, 2-5), del Castrum Rauracense en Augst (Mutz, 1983: 26-28, Abb. 14-16), un ejemplar hallado en Campogalliano (Corti, Pallante y Tarpini, 2001: 272, fig. 200, 6), otro sin procedencia conocida del Museo Nazionale Romano (Candilio, 1985: 215, fig. 194) y finalmente otro procedente del tesoro descubierto en 1883 en la región de Polhograjski en las Dolomitas eslovenas (Božič, 2000).

Se conocen pequeñas librae sin contrapeso y fiel perforado en el Museo de Navarra procedentes de Castejón (Erice Lacabe, 1986: 216, Lám. IX, 1) y en el Museo de Sevilla sin procedencia conocida
(Fernández Gómez, 1991: 380, fig. 5). Del yacimiento esloveno de Polhov Gradec procede una pieza con un fiel perforado notablemente más elaborado que los ejemplares segobrigenses y decorado más profusamente en su fulcrum, cuyos paralelos más directos se establecen en sendos ejemplares hallados en las ciudades de Carnuntum en Panonia y de Herakleia Lincestis en Macedonia (Božič, 2005: 328, Abb 16.1, Abb. 36) y en Conimbriga (Ponte, 1979: 131 n 16 , Est. II, 16).

De Pompaelo procede una pequeña balanza de orfebre (Mezquíriz, 1958: 298 n 16, fig. 139: 16; Erice Lacabe, 1986: 216, fig. 5, 6, Lám. IX, 3) que se data en el siglo IV d.C. Posee en la cara superior de su scapus una pestaña perforada para sujeción del fulcrum. Carece de fiel y conserva un único platillo suspendido por tres cadenillas de bronce. Tampoco presenta fiel una balanza hallada en Osuna que conserva los dos platillos y que se fecha, basándose en la hipótesis de que sirviera para pesar áureos, en época flavia o entre el 150-175 d. C. (Chaves, 1982: 222, fig. 2). Ambas presentan dispositivos de suspensión muy similares al de otras dos piezas procedentes del fuerte romano de South Shields, en la desembocadura del río Tyne (Allason-Jones y Miket, 1984: 172-175 n 3.468, 3.483 ) y al de dos de los ejemplares hallados en la región de Módena, uno procedente de Mirandola y el otro de Finale Emila (Corti, Pallante y Tarpini, 2001: 272, fig. 200, 3 y 5), resultando los paralelos más directos de nuestra balanza $\mathrm{n}^{\circ} .2$.

La pesa $n^{\circ} .24$ del catálogo es la única pieza realizada en bronce. Es de forma troncocónica de base circular y presenta una bolita esférica en la parte superior como elemento de aprehensión. Tiene una cuidada manufactura por lo que se relaciona con una balanza de precisión. Su peso, de $28 \mathrm{~g}$, equivale básicamente a 1 uncia. Su forma ligeramente acampanada recuerda a los denominados «pesi a ciotola», aunque estos presentan su interior hueco para poder ser apiladas consecutivamente componiendo juegos de pesas calibradas (Glaser, 1999; Găzdac y Wright, 2009).

El uso de las pesas $n^{\circ} .22$ y n ${ }^{\circ} .23$ del catálogo también se pone en relación con librae de pequeño tamaño. Presentan una elaboración y una morfología poco esmeradas por lo que deben considerarse productos absolutamente locales. El peso de la pesa $n^{\circ} .22$ es de $70,7 \mathrm{~g}$, que equivale aproximadamente a 2,5 unciae; el de la pesa $n^{\circ} .23$ de 81,4 g o 3 unciae, correspondiente a un quadrans o cuarto de libra. Para la pieza cónica $\mathrm{n}^{\mathrm{o}}$. 22 proponemos como paralelos los ejemplares publicados por Corti, Pallante y Tarpini (2001: 304-307, fig. 225: 2 y 3 ) procedentes de Finale Emilia en la región de Módena aun cuando estas disponen de orificio de suspensión en su vértice superior.

La gran pesa procedente de Huete inventariada con el $n^{\circ} .25$ del catálogo pertenece al grupo de los pondera lapídeos destinados a balanzas de brazos iguales de cierto porte. Se trata de un ejemplar eminentemente práctico que no presenta ningún tipo de elemento decorativo. $\mathrm{Su}$ asa está concebida como un simple 
dispositivo de aprehensión y se reduce a un cuadradillo de hierro modelado en sus extremos para unirse a los cáncamos fijados en la parte superior de la pesa. Está elaborado en piedra caliza de la zona por lo que debe considerarse un producto local. El lateral inferior de uno de los extremos largos presenta un corte oblicuo en su desarrollo curvo que representa una pérdida de parte de su masa y que parece corresponder a la calibración de la pieza tras el aporte de peso producido por la fijación del asa. Su peso total asciende a 13,4 kg equivalentes aproximadamente a 41 libras romanas.

Está descontextualizada al corresponder a un depósito antiguo del Museo de Segóbriga pero su hallazgo se relaciona con otros dos ejemplares que proceden del yacimiento existente en el Cerro de Alvarfáñez, muy próximo a la localidad de Huete, y que pertenecen a la colección de la Real Academia de la Historia. El primero de ellos es un ponderal de serpentina verde hemisférico de 50 libras de peso que posee un asa de bronce decorada con representación de pulgares y cabezas de cisne (Abascal y Gimeno, 2000: 113-114 $\mathrm{n}^{\mathrm{o}}$ 146a; Jiménez Guijarro, 2002:234-235 nº 63). El segundo es de bronce, tiene forma de esfera truncada por dos de sus lados y presenta la indicación de su peso de 10 libras (Abascal y Gimeno, 2000: 114 n $^{\circ} 146 b$ ).

Entre todos los pesos y contrapesos hallados en Segobriga destaca el catalogado con el $\mathrm{n}^{\circ}$. 12, que es una pieza esferoidal de plomo dotada de una argolla de hierro que aún conserva el eslabón alargado con el que se suspendería del instrumento. En la pared de la pesa y junto al asa de hierro, en posición oblicua, presenta la inscripción I IIIIIS(emis), que corresponde a su peso expresado en libras mediante la expresión $I$, como indicación a 10 libras, seguida de IIIIIS como representación de 5,5 libras más, lo que se aproxima a su peso total de $4,875 \mathrm{~kg}$ (circa 15 libras). En todo caso, el valor del peso en los contrapesos de romana no resulta significativo ya que su momento de fuerza resulta de su distancia con respecto al fulcro de la palanca constituida por el instrumento así como por la posición relativa de la carga en el mismo. Como aproximación a la capacidad de la statera a la que pudo pertenecer sirva el estudio de Lazzarini (1948: 237) quien describe una statera en el Antiquarium Comunale di Roma de 1,40 $\mathrm{m}$ de brazo y aequipondium de $4,486 \mathrm{~kg}$ con la que estima una pesada máxima de $84 \mathrm{~kg}$, valor sin duda muy alejado de los $1.500 \mathrm{~kg}$ calculados para la romana asociada al aequipondium procedente del puerto de Tarraco (Rodríguez Martorell y Ruiz de Arbulo, 2016: 170-171), que hasta el momento es el contrapeso más grande conocido de época romana.

Este tipo de aequipondia no figurado corresponde a staterae del tipo Osterburken de Franken (1993: 8589), consideradas las primeras producciones seriadas de instrumental de pesar. Se fechan a partir de la segunda mitad del siglo II y a lo largo de todo el siglo III, difundiéndose ampliamente por todo el imperio incluyendo Hispania, Gallia, Britania, Germania, Raetia, Italia, Panonia, Asia Menor, Palestina, Egipto y el norte de África. El ejemplar de Segobriga se recuperó del interior de un silo de época tardovisigoda correspondiente a la reocupación del área del criptopórtico existente junto a las Termas del Teatro (Abascal, Alberola, Cebrián y Hortelano, 2010: 55).

Dos ejemplares recuperados en excavaciones de yacimientos croatas recientemente publicados constituyen los paralelos más directos. De Vodice procede una statera con un contrapeso muy similar, aunque de tamaño más reducido pues su peso tan solo alcanza los 1,486 kg (Pflaum, 2007: 287-288 n 15, fig. 11, Pl. 1). En Humščak tan solo se conoce el aequipondium, de 768 g, que se fecha en época tardía (Šimek, 2011:1519:sl. 3).

Los contrapesos $n^{\circ} .5$ y no .6 del catálogo son simples pesas de plomo fundido con orificios de suspensión abiertos en sus cuerpos en el mismo proceso de fabricación. Morfológicamente podrían corresponder a pesas de telar pero en el caso de la pieza $n^{\circ} .5$ consideramos que su peso de $3,350 \mathrm{~kg}$ resulta excesivo para tal fin. Podría haber servido como aequipondium de una balanza de brazos asimétricos aunque tampoco puede descartarse su función como contrapeso en algún ingenio mecánico no determinado. En el caso de la pesa $n^{0} .6$ descartamos su relación con la actividad textil debido a su lugar de hallazgo, el escenario de un hecho bélico en el marco de las guerras sertorianas, aunque formalmente se asemeja a piezas tradicionalmente vinculadas a tal fin o a la pesca (Romualdi, 1989: 162). Su función probablemente deba relacionarse, al igual que los pequeños contrapesos $\mathrm{n}^{\circ} .11, \mathrm{n}^{\mathrm{o}}$. $13 \mathrm{y} \mathrm{n}^{\circ} .17$ comentados anteriormente, con balanzas de precisión empleadas en la elaboración de proyectiles de plomo.

Las pesas catalogadas con $\operatorname{los} \mathrm{n}^{\mathrm{o}} .7$ a 10 se vinculan a la actividad textil. Todas son troncopiramidales de base cuadrada y presentan orificios de suspensión abiertos en el extremo superior de sus cuerpos. Su peso oscila entre 69,6 y 110,4 g lo que equivaldría a entre 2,5 y 4 unciae. Su uso se relaciona con el tensado de los hilos de la urdimbre en los telares verticales, sustituyendo a las pesas más corrientes de cerámica en los aparatos de dimensiones más reducidas. Son frecuentes en ambientes domésticos y artesanales. Las pesas $n^{\circ} .7$ y 8 proceden de los rellenos de nivelación vertidos sobre la necrópolis noroccidental para la construcción del circo en la segunda mitad del siglo II d.C., considerándose materiales ya amortizados en ese momento (Ruiz de Arbulo, Cebrián y Hortelano, 2009: 69-70). La pieza $n^{\circ} .9$ se recuperó en una nivelación fechada en época flavia, que cegó el criptopórtico de servicio existente junto a las Termas del Teatro con motivo de la inauguración de las Termas Monumentales (Abascal, Alberola, Cebrián y Hortelano, 2010: 4446) y la $n^{\circ} .10$ fue hallada muy próxima en el interior de una zanja de expolio de época visigoda.

El resto de materiales corresponde a pequeños contrapesos cuya morfología diversa queda definida en el catálogo. Se aportan como paralelos significativos 

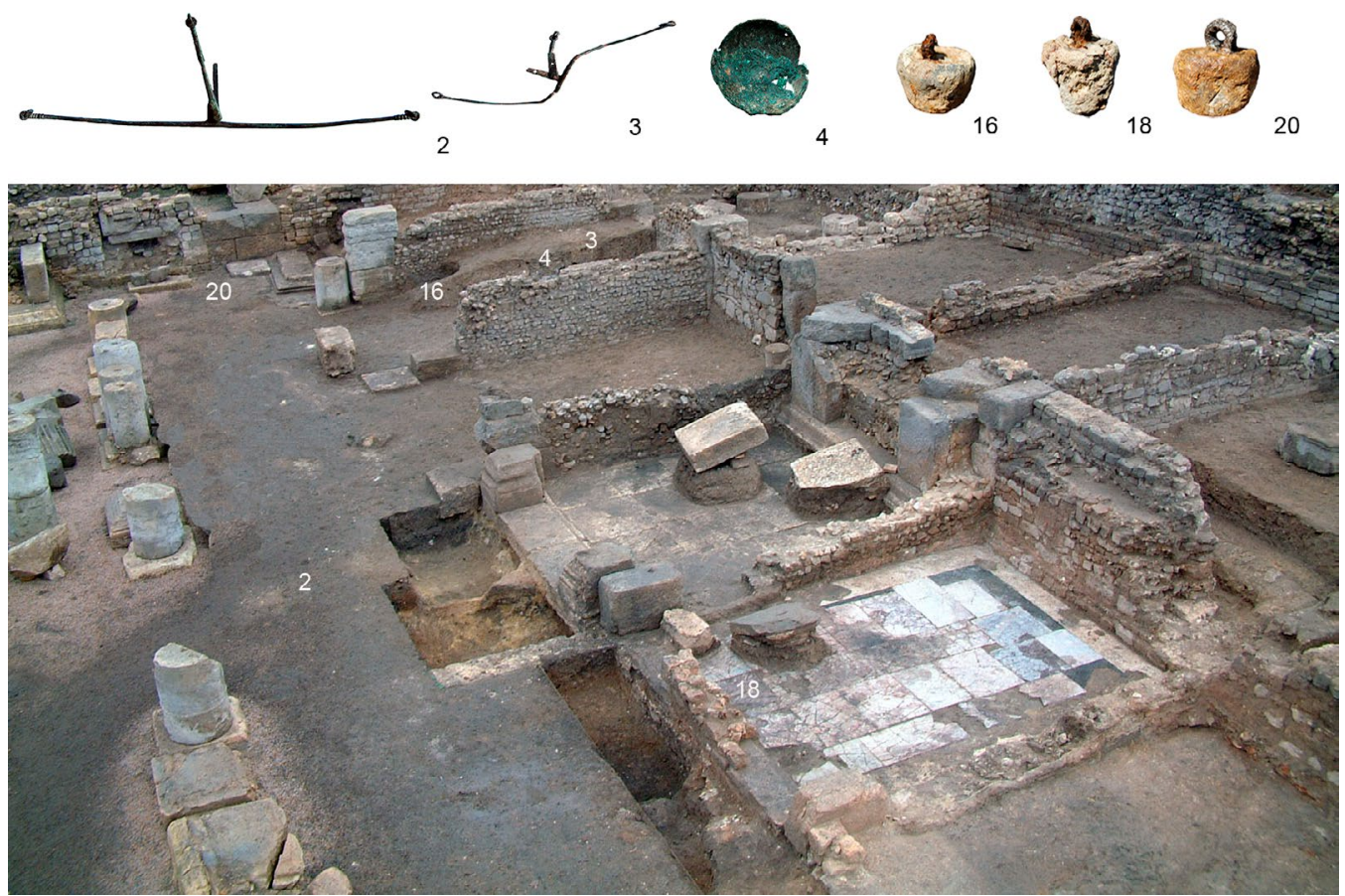

Figura 10: Contexto del hallazgo de varios elementos de pesar en las denominadas tabernae del foro de Segobriga.

materiales del Museo de Sevilla (Fernández Gómez, 1991: fig. 7,16 y 17), procedentes del poblado ibero romano de Sant Josep en La Valld'Uixó (Rosas Artola, 1983: 214 n $^{\circ} 59$ y fig. 5, 59), de Conimbriga (Ponte, 1979: 131-132, Est. II, 18, 19: 23 y 30) y de la región rumana de Dobruja (Custurea, 2003: $676 \mathrm{n}^{\circ} 14,16$ y 18, Pl. II, 14, 16 y 18).

Una última consideración puede realizarse en relación al contexto de hallazgo de las librae $\mathrm{n}^{\circ} .2 \mathrm{y} \mathrm{n}^{\circ}$. 3 , el lanx $\mathrm{n}^{\circ} .4$ de esta última, y los contrapesos de staterae $\mathrm{n}^{\circ} .16, \mathrm{n}^{\circ} .18 \mathrm{y} \mathrm{n}^{\circ} .20$ (Fig. 10). Todas estas piezas fueron recuperadas en las tabernae y pórtico meridional del foro en niveles del siglo III d. C., fecha en la que se instaló un horno para fundición de metales en la $1^{\mathrm{a}}$ taberna, la más cercana a la basílica, asociado a un canal de agua. Su hallazgo, junto a algunos fragmentos de bronce de estatuas broncíneas procedentes de procesos de spolia del foro (Noguera, 2012: $\mathrm{n}^{\circ}$. 223-228), hierro y plomo, en el nivel de uso de este período temporal conformado por un pavimento de tierra apisonada, permite relacionarlas con la nueva actividad artesanal emplazada en el espacio público de Segobriga.

\section{REFERENCIAS}

Abascal, J. M., Alberola, A., Cebrián, R. y Hortelano, I. (2010). Segóbriga 2009. Resumen de las intervenciones arqueológicas. Cuenca: Consorcio Parque Arqueológico de Segóbriga.

Abascal, J. M. y Gimeno, H. (2000). Epigrafía Hispánica: catálogo del Gabinete de Antigüedades. Madrid: Real Academia de la Historia.
Alarçao, J. y Étienne, R. (1979). Fouilles de Conimbriga VII. Trouvailles diverses. Conclusions générales. Paris: Boccard.

Albiach, R. y Pérez Mínguez, R. (2009). La statera de la colección Federico Motos. Velezana, 28, 42-47.

Allason-Jones, L. y Miket, R. (1984).The Catalogue of small finds from South Shields Roman Fort. Newcastle upon Tyne.

Aranegui, C. (1989). Statera romana hallada en Valencia. Archivo de Prehistoria Levantina, XIX, 263-264.

Aranegui, C. (1991). Statera de bronce. En C. Aranegui (Coord.). Saguntum y el mar (pp. 107-109). Valencia: Generalitat Valenciana.

Arribas, A., Tarradell, M. y Woods, E. (1978). Pollentia II. Excavaciones en Sa Portella, Alcudia, Mallorca. Excavaciones Arqueológicas en España, 98. Madrid: Centro Superior de Investigaciones Científicas.

Božić, D. (2000). Eines pätrömische Pinzetteo der Waageschere?. Instrumentum. Bulletin du Groupe de travail européen sur l'artisanat et les productions manufacturées dans l'Antiquité, 12, 30. Recuperado de: https://www.academia. $\mathrm{edu} / 1828973$

Božić, D. (2005). Die spätrömischen Hortfunde von der Gora oberhalb von Polhov Gradec. Arheološkivestnik, 56, 293-368.

Caballero, L. (1990). Los Bronces Romanos en España. Catálogo de la exposición en el Palacio de Velázquez. Madrid: Ministerio de Cultura.

Candilio, D. (1985). I materiali del commercio al minuto. En R. Bussi y V. Vandelli (Eds.). Misurare la terra: centuriazione e coloni nel mondo romano; città, agricoltura, 
commercio; materiali da Roma e dal suburbio (pp. 211223). Módena: Edizioni Panini.

Cebrián, R.(2014). Estudio de los proyectiles de plomo procedentes del entorno de Segobriba (Saelices, Hispania Citerior). En E. Martínez Ruiz y J. Cantera (Dirs.). Perspectivas y novedades de la Historia Militar. Una aproximación global. Tomo I. (Madrid, 2013) (pp. 171-190). Madrid: Ministerio de Defensa.

Chaves, F. (1982). Instrumentos de medida romanos hallados en Andalucía. Zephyrvs, XXXIV-XXXV, 219-222.

Chaves, F. y Pliego, R. (2007). Instrumentos de medida de pesos en la Hispania antigua. Sautuola, XIII, 237-250.

Corte, M. della (1912). Librae pompeianae; ricostruzione di due grosse bilance in legno e bronzo.Monumenti Antichi, $21,5-42$.

Corti, C. (2001a). Pesi e contrappesi. En C. Corti y M. Giordani (Eds). Pondera. Pesi e mesure nell'Antichità (pp. 191212). Módena: Museo della Bilancia.

Corti, C. (2001b). Pesi e misure nell'economía del territorio. En C. Corti y M. Giordani (Eds). Pondera. Pesi e mesure nell'Antichità (pp. 331-337). Módena: Museo della Bilancia.

Corti, C., Pallante, P. y Tarpini, R. (2001). Bilance, stadere, pesi e contrapesi nel Modenese En C. Corti y M. Giordani (Eds). Pondera. Pesi e mesure nell'Antichità (pp. 271-313). Módena: Museo della Bilancia.

Custurea, G. (2003). Ponduri antice şi medievale descoperite recent în Dobrogea. Pontica, 35-36, 672-683.

Damerow, P. Renn, J., Rieger, S. y Weinig, P. (2002). Mechanical knowledge and Pompeian balances. En G. Castagnetti, A. Ciarallo y J. Renn (Eds.). Homo Faber: Studies on Nature, Technology, and Science at the time of Pompeii; presented at a conference at the Deutsches Museum Munich (Munich 2000) (pp. 93-108). Studi della Soprintendenza archeologica di Pompei, 6. Roma: «L'Erma» di Bretschneider.

Daremberg. E. y Saglio, E. (1900). Dictionnaire des Antiquités Grecques et Romaines. Paris.

Erice Lacabe, $\mathrm{M}^{\mathrm{a}}$ R. (1986). Bronces romanos del Museo de Navarra. Trabajos de arqueología navarra, 5, 195-235.

Erice Lacabe, $M^{a}$ R. (2014). Una pesa de balanza figurada procedente de Sofuentes, Zaragoza. En A. Duplá, M ${ }^{\mathrm{a}}$ V. Escribano, L. Sancho y $\mathrm{M}^{\mathrm{a}} \mathrm{A}$. Villacampa (Eds.). Miscelánea de estudios en homenaje a Guillermo Fatás Cabeza (pp. 257-263). Zaragoza: Institución Fernando el Católico.

Fernández Gómez, F. (1991). Balanzas y romanas de bronce en los mercadillos de antigüedades de Sevilla. Trabajos de Prehistoria, 48, 373-382.

Franken, N. (1993). Zur Typologie der antiker Schnellwaagen. Bonner Jahrbücher, 193, 69-120.

Găzdac, C. y Wright, B. (2009). Counterfeiting official roman weights. The inscribed cup-weight from Porolissvm. Ephemeris Napocensis, XIX, 183-190.
Glaser, F. (1999). Fast ein Unikat: Römische Kapselgewichte aus Feldkirchen, Rudolfinum. Jahrbuch des Landesmuseums fur Karnten, 1999, 58-62.

Hernández Prieto, Mª A. (1984). Objetos metálicos de época romana aparecidos en Calahorra. En Calahorra: bimilenario de su fundación. Actas del I Symposium de Historia de Calahorra (pp. 161-172). Madrid: Ministerio de Cultura.

Jiménez Guijarro, J. (2002). Ponderal romano de piedra. En. M. Almagro-Gorbea (Ed.). Tesoros de la Real Academia de la Historia (pp. 234-235). Madrid: Real Academia de la Historia.

Lazzarini, M. (1948). Le bilance romane del Museo Nazionale e dell'Antiquarium Comunale di Roma. Atti della Accademia Nazionale dei Lincei, Classe di Scienzi Morali, Storiche e Filosofiche, VIII(3), 221-254.

Mezquiriz, Ma A. (1958). La excavación estratigráfica de Pompaelo I: campaña de 1956. Pamplona: Diputación Foral de Navarra.

Mutz, A. (1983). Römische Waagen und Gewichte aus Augst und Kaiseraugst. Augster Museumshefte, 6. Augst: Römermuseum. Recuperado de: http://www.augustaraurica. ch/fileadmin/user upload/2 Arch\%C3\%A4ologie/7 Literatur\%20und $\% \overline{2}$ 0Verlag/03_Augster_Museumshefte/ AMH06.pdf

Noguera, J. M. (2012). Segobriga (Provincia de Cuenca, Hispania Citerior). Corpus Signorum Imperii Romani. Corpus de Esculturas del Imperio Romano, vol. I, fasc. 4. Tarragona: Institut Català d'Arqueologia Clàssica.

Palol, P. de (1950). Los bronces del depósito hallado en el Collet de Sant Antoni de Calonge, conservados en el Museo de Gerona. Memorias de los Museos Arqueológicos Provinciales, $I X-X$, 66-74.

Pares, Ch. (2013). Weighing, commodification and money. En H. Fokkens y A. Harding (Eds.). The Oxford Handbook of the European Bronze Age (pp. 508-523). Oxford: Oxford University Press.

Pasquale, G. di (1998). La stadera un problema di filologia, storia ed archeologia. Nuncius. Annali di storia della scien$z a, 13(2), 657-666$.

Pasquale, G. di (2004). Tecnologia e meccanica. Trasmissione dei saperi tecnici dall'età ellenistica al mondo romano. Biblioteca di Nuncius, 55. Florencia: Università di Cagliari. Recuperado en: https://www.academia.edu/1129980.

Pflaum, V. (2007). The supposed Late Roman hoard of tolos and a steelyard from Vodice near Kalce. Arheološkivestnik, 58(1), 285-332.

Ponte, S. da (1979). Balanças e pesos de Conimbriga. Conimbriga, 18, 121-132.

Pontiroli, G. (1990). Pondera, staterae, aqequipondia nel Museo Civico di Cremona. Epigraphica, LII, 178-200.

Pozo, S. F. (1994). Pesas de balanza romanas de la Península Ibérica y las Islas Baleares. Akten der 10. Internationalen Tagungüber Antike Bronzen (Freiburg, 1988) (pp. 337-345). Stuttgart: Kommissionsverlag K. Theiss. 
Pozo, S. F. (2002). Varia arqueológica de la provincia Baeti$c a$. Bronces romanos inéditos. Grandes bronces. Estatuillas. Mobiliario doméstico. Amuletos fálicos. Espejos. Balanzas. Contrapesos. Asas y apliques de sítulas. Atalaje de caballerías. Antiquitas, 14, 69-121.

Rodríguez González, X. (2010). Balanza romana. Recuperado de: http://www.musarqourense.xunta.es/wp-content/ files_mf/pm_2010_04esp.pdf

Rodríguez Martorell, F. y Ruiz de Arbulo, J. (2016). Un aequipondium de peso excepcional y la balanza pública del puerto de Tarraco. Archivo Español de Arqueología, 89, 163-180. DOI: http://dx.doi.org/10.3989/aespa.089.016.008

Romualdi, A. (1989). Il patrimonio disperso: reperti archeologici sequestrati dalla guardia di finanza. Catalogo della mostra Piombino (Roma, 1989). Roma: L'Erma di Bretschneider.

Rosas Artola, M. (1983). El mobiliari metàl-lic del poblat ibero-romà de Sant Josep. Cuadernos de Prehistoria y Arqueología Castellonenses, 7, 197-218.

Ruiz de Arbulo, J. Cebrián, R. y Hortelano, I. (2009). El circo romano de Segobriga, Saelices, Cuenca. Arquitectura, estratigrafia y función. Cuenca: Consorcio Parque Arqueológico de Segóbriga.
Sentandreu Gimeno, M. C. (1959). Estátera romana del Museo de Prehistoria de Valencia Valencia. Archivo de Prehistoria Levantina, VIII, 197-202.

Šimek, M. (2011). Uteg zabrzu vagu - arheološki nalaz sa Humščaka. Historia Varasdiensis: časopis za varaždinsku povjesnicu, 1(1), 13-26.

Sutto, M. (2016). I pesi parlano. I pondera metallici e lapidei iscritti del Museo Archeologico Nazionale di Aquileia. En M. Buora y S. Magnani (Eds.). Le iscrizioni con funzione didascalico-esplicativa. Committente, destinatario, contenuto $e$ descrizione dell'oggetto nell'instrvmentvm inscriptvm. Atti del VI Incontro Instrvmenta Inscripta (Aquileia, 2015) (pp. 291-314). Antichità Altoadriatiche, LXXXIII. Roma: Arbor Sapientiae.

Tarpini, R. (2001). Bilance e stadere. En C. Corti y M. Giordani (Eds). Pondera. Pesi e mesure nell'Antichità (pp. 179190). Módena: Museo della Bilancia.

Tyrell, R. (2015). Lead weights. En M. Atkinson y S. J. Preston (Eds.). Heybridge: A Late Iron Age and Roman Settlement, Excavations at Elms Farm 1993-5. Internet Archaeology, 40. DOI: http://dx.doi.org/10.11141/ia.40.1.tyrrell8 